\title{
Invention and Comparison of Patenting and the Examination Guidelines about Inventive Step in Japan, the U.S.A. and the EU-Based on the Opinion Focusing on Principles and Their Use
}

\author{
Kotaro Kageyama \\ Kageyama International Law \& Patent Firm, Tokyo, Japan \\ Email:kageyama@kageyamalaw.com
}

How to cite this paper: Kageyama, K. (2019). Invention and Comparison of $\mathrm{Pa}$ tenting and the Examination Guidelines about Inventive Step in Japan, the U.S.A. and the EU-Based on the Opinion Focusing on Principles and Their Use. Beijing Law Review, 10, 539-578.

https://doi.org/10.4236/blr.2019.103033

Received: May 17, 2019

Accepted: June 11, 2019

Published: June 14, 2019

Copyright $\odot 2019$ by author(s) and Scientific Research Publishing Inc. This work is licensed under the Creative Commons Attribution International License (CC BY 4.0).

http://creativecommons.org/licenses/by/4.0/

\begin{abstract}
1) Author, as to inventions, categorized into physical-object inventions whose shape, structure etc. were focused on and material inventions whose characteristics were focused on, according to their appearances and properties. Six factors, that is, composition, shape, structure of an article, physical properties, chemical properties of a material, and their transformation are extracted from this categorization. 2) Author also found out that inventions could be analyzed to the view of principle, use of principle and the ways of its use (which is called "principle use"), attaching the importance to principle based on the process of the establishment of inventions. Author formulated that technology and inventions could be put in order two-dimensionally, given an abstraction and normalized, setting the above 6 factors and principle use as two axes (which is called the Opinion). On the basis of the Opinion, Author analyzed, as to the concept of an invention, its patentability (subject matter eligibility) and inventive step in Japan, the U.S.A. and EU. As to the inventive step, Author analyzed the differences in the framework of determination, and the obstructive factors and the prevention of hindsight which specifically tend to become problems in the examination guideline, citing court decisions. The setting of the objective technical problem, which is used in the EU, aims at making the objection of the judgment of inventive actions (subjective); on the other hand, the Opinion can set the objective facts of principle use as a unified criterion, which may lead to more articulate decisions. By using the Opinion, the recognition of an inventor, the determination of inventive step, and furthermore, the interpretation of claims can be made more rationally. It is hoped that the consideration and its result using the Opinion will be practically used in the world.
\end{abstract}




\section{Keywords}

Patentability (Subject Matter Eligibility), Objective Technical Problem, Criterion of Determination for the Inventive Step (Teaching, Suggestion, Motivation), Obstructive Factor, Prevention of Hindsight

\section{Introduction and the Opinion}

Author has considered an invention and has published the following opinion (view) until now (hereinafter, referred to as "the Opinion". The Opinion is composed of Opinion 1 and Opinion 2).

This article will consider the concept of an invention, its eligibility for a patent and inventive step in Japan, U.S.A. and EU (hereinafter, "the" is omitted in "the U.S.A.," "the EU" and "the U.K."), depending on the Opinion. It can bring a more objective and unified interpretation about them than before. In this article, the above consideration and its result based on the Opinion are called as "the Opinion," also for convenience.

1) Opinion 1 is the viewpoint in which an invention can be categorized into either a physical-object invention or a material invention, based on how it looks, that is, the appearance and property of an invention. A physical-object invention is an invention that focuses on the shape, physical structure and the combination of articles, such as circuits (its appearances). A material invention (invention for substance) is an invention that focuses on the properties of an article (including their transformation) that are used in the invention.

There are main 6 factors (the "1) combination, 2) shape, 3) structure of an article, 4) physical properties, 5) chemical properties, and 6) transformation of properties of a material") which are extracted from the said categorization (hereinafter, "6 factors"). Because the above 6 factors are typical examples, they can be used in the way of deleting a part or making a part more detailed according to a case.

Opinion 2 analyzes the formation process of an invention with an emphasis on the principle (typically that of physics and chemistry) involved in the invention. Considering together with a definition of an invention to be mentioned later, because an invention can be considered as "the ways of use of principle" to attain the purpose (to solve the problem), it is analyzed into the parts of a "principle", "use of the principle" and "ways of use" (hereinafter "(the) principles and their use" shortly). Of course, they are for improving the utility. It can also be said that they are the essence of an invention with 6 factors.

2) The meaning of adopting principles and their use with regard to formation of an invention and patenting is as follows.

First, during the formation of an invention, the occurring phenomenon should be observed and analyzed with the aim of finding a solution in a technical defect or for a technical improvement. In there, physical, chemical and technol- 
ogical principles which have caused the said phenomenon are investigated. Also, consideration is added, and the conception for the solution or improvement is made. An experiment is repeated according to necessity, and invention is formed completely. In this process, the consideration about the principles and their use of the physics, chemistry, and technology of invention is made.

Therefore, when patenting (making an invention to be patented) also, principles and their use should be set on this basis.

3) Here, it can be considered that principles and their use include both those as a whole and those as a part. Principles and their use as a whole consist of those as a part. Although principles and their use as a whole may be the simple sum of those as a part in some cases, in other cases, a new effect may be caused by the interaction of principles and their use as a part or the conventional effect may decrease.

When several technologies or inventions are compared, a method which divides them into each element and compares them correspondingly (theory of dividing invention into its elements) is used. Technology and invention, as a whole, correspond to the principles and their use as a whole, and the principles and their use supporting each element correspond to the principles and their use as a part in many cases. In this case, it must be taken into consideration that a difference arises in the principles and their use by the interaction between the parts and the effect (utility) of technology and invention as a whole may be different.

4) The above 6 factors and principles and their use can be shown in 2 axes (coordinates); thereby, technology and invention are arranged in two dimensions and can be used as abstraction as the occasion demands. Furthermore, it can be helpful to make a norm (example guidelines etc.) (e.g., (2.4) 4), (4.5) 5)). In particular, the portion (column B and C) of Table 1 can become an invention.

Principles and their use as a whole and as a part are those which add the derivative axis about principles and their use.

In addition, in international Patent Classification (IPC), the technical subjects of invention concern either a) the intrinsic nature or function of a thing (function-oriented) or b) the way a thing is used or applied (application-oriented). ${ }^{1}$

In relation to the Opinion, it is considered that the above a) corresponds to an invention regarding "use (of principle)", and b) corresponds to invention regarding "ways of use". "Ways of use" is a relation between a thing which causes a principle and a thing which receives a principle etc., for example, in a scene (situation) where a principle is applied. It is thought that a more concrete classification of types is also possible.

From the further analysis, the column A "principle" in Table 1 is related to, beginning with technology/engineering to science. In short, from the viewpoint of the use of science technology, it shows the progress of: science $\rightarrow$ technology $\rightarrow$ engineering $\rightarrow$ invention $\rightarrow$ patent, and the order of "principle", "use of principle", ${ }^{1}$ WIPO “Guide to the international patent classification" (version 2018) p. 22. 
Table 1. Two-dimensional arrangement of technology and invention.

\begin{tabular}{|c|c|c|c|c|c|c|}
\hline \multirow[b]{2}{*}{$\begin{array}{l}\text { Principles } \\
\text { and their use }\end{array}$} & \multirow[b]{2}{*}{ a) combination } & \multirow[b]{2}{*}{ b) shape } & \multirow[b]{2}{*}{ c) structure } & \multicolumn{2}{|c|}{ property } & \multirow{2}{*}{$\begin{array}{l}\text { f) transformation of } \\
\text { property }\end{array}$} \\
\hline & & & & d) physical & e) chemical & \\
\hline \multicolumn{7}{|l|}{ A) Principle } \\
\hline \multicolumn{7}{|c|}{ B) Use of principle } \\
\hline C) Ways of us & & & & & & \\
\hline
\end{tabular}

and "ways of use" in the vertical coordinate of the above Table is in line with this flow of the progress ${ }^{2}$.

5) Although a principle is objective as a fact, because patent law and examination guidelines aim at its use, their regulations are formed using wordings, such as "function" which shows the use of principle, "effect" which shows its result, and "operation" which shows the ways of use. It can be said that these wordings, "function", "effect" and "operation" have more practical meanings and have points which influence the five senses.

However, "principle", "principles of their use" and "ways of use" utilized by the Opinion can be presented as what was abstracted and made in normative form based on the real fact. Compared with the terms used in the abovementioned patent law and examination guidelines, they seem to be able to provide a clearer technical meaning in invention and patenting. It is useful that a real fact can be made abstract for the argument on the same wavelength between the interested persons (an applicant, an examiner, a judge and the other persons).

6) In addition, in some inventions, a principle is not known. In these cases, "a reproducible phenomenon" is replaced with a principle and is adopted. The said cases are frequent in material invention which is formed by an experiment (Kageyama, 2018a). In this article, to make a discussion simpler the principles and their use are used and a discussion is made.

Regarding the explanation from the fundamental portion of the Opinion, please refer to Author's work "Unified Approach for Inventive Step and Claim Interpretation-Analysis based on the physical/chemical principle and ways of its use, and the categorization of the physical-object/material invention" (Kageyama, 2018b) (hereafter "Unified Interpretation Book" for short).

\section{Invention and Patenting}

\subsection{Invention}

The Japanese Patent Law defines an invention as "the (highly advanced) creation of technical ideas utilizing the laws of nature"3 (Article 2, Paragraph 1). The laws of nature are typically the principles of physics and chemistry.

The above definition of an invention given in the Japanese Patent Law is quite ${ }^{2}$ This viewpoint was not mentioned in the past analysis on the Opinion, therefore it is newly explained in this paper.

${ }^{3}$ The term "(highly advanced)" in the definition indicates that an invention should be advanced compared to a "device", which is a small invention, so to speak, under the Japanese Utility Model Law. 
concise and to the point (in this article, without special notice, law means a patent law). Such a positive and brief definition about invention is not regulated by U.S.A., Britain, Germany, EU and any other countries.

In practice, an invention is formed by a process comprised of (1) conception and (2) embodiment of the conception, to attain the purpose of the invention.

Based on Opinion 2, an invention is understood as the "manifestation of ways of use of principle". "Manifestation" means creation (thing), and the most important part of an invention is "ways of use of principle". In this article, this is considered, analyzing into a "principle", "use of principle" and "ways of use". Among them, an invention corresponds especially to "use of principle" and "ways of use".

Arthur, W. B., economist who was awarded the International Schumpeter Award in 1990, said that "At the heart of invention lies the act of ...seeing a suitable principle that will do the job. The rest... is standard engineering" (Brian Arthur, 2009), and was thinking with emphasis on discovery of a principle. According to Author's opinion, generally, if a principle can be found out, it will be thought that the technology of carrying it out is possible at any rate. In other words, an invention will be accomplished in that possible range.

\subsection{A Relation with a Person Who Invented (Inventor)}

In U.S.A. and some other countries, because there is no definition about invention, the meaning of invention is considered from the semantic content of an "inventor". When it is thought that the invention was made by two or more persons (joint invention), there are questions that occur: who are inventors and how much is the extent of share in patent right? Therefore, identification of (joint) inventor must be inquired in the semantic content of the invention which is an object of the act of the persons involved.

1) Based on the Opinion, an inventor is a person who contributed to "conception based on a principle" or "establishing a model" from formation process of invention described in the above (2.1) (Kageyama, 2015). The former is the one who made a conception, and the latter is the one who embodied the conception.

2) According to the conventional court decision of Japan, the inventor is considered as someone "who had obtained technical knowledge to a feasible degree on the matter considered as the technical characteristics of the invention" (Osaka district court on 23April, 2002) ${ }^{4}$. However the word of "technical knowledge" is not concrete.

3) Court decision in U.S.A. expresses more concretely stated below.

Although an inventor is a person who made a conception of "subject matter of an invention", expressed below (2.3) 1), "definite and permanent idea of an operative invention" is required for a conception (Sewall. v. Walters). ${ }^{5}$

As mentioned above, the essence of "definite and permanent idea of an operative invention" is exactly "a principle". Therefore, it is common for the Opinion ${ }^{4}$ Santoku corporation v. A (2002) Hanrei Jihō No.1825, p. 130.

${ }^{5}$ Sewall v G. Walters, 21 F.3d 411 (Fed. Cir.) 1994, paragraph 21. 
to state the meaning of invention and the significant concern of a principle.

4) Referring to the court decision of Britain, an inventor is a person who performed the quest of "the heart of the invention"6. Although this also seems to correspond to principles and their use, it is an abstract and figurative expression.

\subsection{Inventions Patentable and Discovery under U.S.A. Patent Law}

1) U.S.A. Patent Law stipulates "Inventions patentable" with an expression "whoever invents or discovers any new and useful process, machine, manufacture, or composite of matter, or any new and useful improvement thereof, may obtain a patent therefor, subject to the conditions and requirements of this title" (35U.S.C.101). These are also called "subject for a patent" or "subject matter of the invention."

In the above, it is considered that a process is a method invention, a machine and products correspond to an invention of an article of a physical-object invention, and a composite correspond to an invention of an article of a material invention (products belong to material invention in some cases). Each step of a process can be considered as a part belonging to physical-object type or to material type. The above is considered to be common to the view of technology and invention described in Opinion 1.

Article 101 mentioned above states "whoever invents or discovers... process, machine, manufacture, or composition of matter, or any... improvement thereof, may obtain a patent therefore...". That is, "discovery" means concerning "process, machine, manufacture, or composition of matter". Therefore, "Discovery" said in U.S.A. Patent Law is comprehended in relation to "use (of principle)" and especially "ways of use" in the Opinion. It does not a discovery of a mere fact (for example, the discovery of the plague bacillus). In addition, "discovery" can be placed in parallel with "invention" as Article 101 above, only if "discovery" is understood like this. Furthermore, the contents of an invention are "use of principle" and/or "ways of use," and a discovery is about them.

“The term 'invention' means invention or discovery” in U.S.A. Patent Law (35 U.S.C. $100(\mathrm{a}))$.

2) By the way, U.S.A. constitution "secures" "for limited Times to Authors and Inventors the exclusive Right to their respective Writings and Discoveries" (Chapter 1, Article 8, paragraph 8). An instance which makes invention a constitutional right is hardly seen all over the world.

Here, only discovery is rather taken up ${ }^{7}$. This is considered as follows.

${ }^{6}$ Markem Corporation \& Anor v. Zipher Ltd [2005] EWCA Civ 267, 769 (22 March 2005).

${ }^{7}$ Regarding protecting copyright and patent right by the constitution in advance of U.S.A. constitution establishment, although T. Jefferson was negative to monopoly at the beginning, J. Madison explained the utility of the protection to Jefferson and sent a letter in which he wrote that "But is it clear that as encouragements to literary works and ingenious discoveries, they (Author's Note: monopolies) are not too valuable to be wholly renounced?" (Founders Online From James Madison to Thomas Jefferson, 17 October 1788). Here too, the term of discovery is used. Although there is an example where discovery is changed for invention among the Japanese translations of U.S.A. constitution, it is not suitable. 
Although both writing and an invention are creations by a man's mental activity, writing is performed fundamentally only in its heart (mind); on the other hand, an invention is formed by recognizing the phenomenon of the outside world. Recognition of the principles and their use extracted from the phenomenon of the outside world is a discovery here ${ }^{8}$.

In the said provision of U.S.A. constitution, a view of "invention from discovery", that is, progressing to invention from discovery is shown. According to this, conception of a principle is thought to be emphasized (Schramm, 2014).

In addition, although protection of copyright is made in their expression, an invention is protected in thought (monopoly is accepted for a limited term). Thus, the instance which admits monopoly of thought can be hardly found. Generally, it is because monopoly of thought results in the prevention of development of culture.

\subsection{Eligibility for Patent Regarding an Invention Related to Living Things}

At the present time, with regard to whether an invention can be a subject (matter) for a patent, one of the technology and invention which is the most problematic is an invention related to living things.

1) According to the Opinion, the essence of invention is understood as principles and their use, so the abovementioned is considered as follows.

The subject (matter) for a patent is a creation and the principles and their use which the creation has differs from those of natural products (a principle of these things are their composition and their products etc., and the use is of those). In other words, when the principles and their use of one thing is acknowledged to be different from those of the natural thing, the said thing can be a subject for patent. Therefore, for example, because the principles and their use of a microbe which was only isolated are not changed to those before isolation, the microbe cannot obtain a patent (for example, it does not add new ways of use. Generally, a slight difference which can be predicted is not evaluated). On the other hand, the combination of various microbes has different principles and their use; therefore, it will have possibility to obtain a patent.

Also, if it is a useful creation, the difference of principles and their use compared with a natural product will become clear (affirmation of the inventive step).

Regarding the inventions related to living things, the mere discovery like an arrangement of a base in a gene (DNA) should not be accepted as a patent. This is because a difference of principles and their use from the natural product does not exist. However, if the recombination etc. differs in principles and their use, it will be able to obtain a patent (a problem of the inventive step will remains depending on the grade of the difference. With regard to an invention relating to a

${ }^{8}$ Incidentally, attaching great emphasis to discovery in U.S.A. is considered to be manifestation of that of the individual mental activity is thought as important. There are some joint inventions. But, since most discoveries are made individually, there are little joint discoveries. 
human body, the problem of ethicality is also added to whether it has patentability).

If the abovementioned is compared typically, the following could be said. The arrangement of DNA in a nature (conventional arrangement) is assumed X-A-B-Y. (1) Here, X-A-Y which removed B, and X-A-B-C-Y which added C will be able to obtain a patent, because those principles and their use differ from the conventional ones.

(2) X-B-A-Y, where A and B are replaced, will raise a problem. If principles and their use are the same, it cannot be said as a creation and therefore it cannot obtain a patent. It could be called a creation if principles and their use which $\mathrm{A}$ and $\mathrm{B}$ have change by a relation with adjoining $\mathrm{X}$ and $\mathrm{Y}$. However, if a difference of principles and their use is in the degree which a person skilled in the art (a person ordinarily skilled in the art of the invention) can predict, it would not have the inventive step.

2) It is considered that U.S.A. Supreme Court decision in the case of Diamond v. Chakrabarty ${ }^{9}$ and court decisions after this case can also be similarly understood.

After the above court decision, the decision in the case of Prometheus (Mayo $)^{10}$ and the decision in the case of Myriad ${ }^{11}$ were sentenced. Also based on these, the argument on the eligibility for a subject of patent had been made in the U.S. Patent and Trademark Office (USPTO) (guidance was made), and examination guidelines ${ }^{12}$ were revised in 2015 and 2017.

In conclusion, although the laws of nature (including a natural principle), natural phenomena and an abstract idea are excluded, these applications (usage) become a subject (matter) for patent. The above application can be understood that it corresponds to "use (of a principle)" or "ways of use" in the Opinion.

In addition, the reason why many problems about things concerning discovery have arisen as mentioned above in U.S.A. seems to be based on U.S.A. Patent Law that makes the discovery the object of an invention. However, a discovery described in U.S.A. Patent Law does not mean the discovery of mere things, and the attention that it means the discovery of use (of a principle), especially, ways of their use must be paid. Moreover, although it seems that there is also an argument on "significantly different or not" from natural products etc., fundamentally this can be understood as the problem of the next stage, that is, the determination for the inventive step.

3) At this point, as will be mentioned (2.5) later, EU has denied clearly that a discovery is an invention (E. P. C. Article 52). However, the meaning of discovery differs from U. S.A. Patent Law.

Examination Guidelines in Japan also ordain that “...mere discoveries, such as discoveries of natural things (e.g., ore) or natural phenomena, for which an in${ }^{9}$ Diamond v. Chakrabarty, 447 U.S. 303 (1980).

${ }^{10}$ Mayo Collaborative Services v. Prometheus Laboratories, Inc., 566 U.S. 66; 132 S. Ct.1289 (2012).

${ }^{11}$ Association for Medical Pathology v. Myriad Gonetics, Inc., 569 U.S. 576; 133 S. Ct. 2107 (2013).

${ }^{12}$ Manual of Patent Examination Procedure (M.P.E.P.) (U.S.A.), July 2015 Update: Subject Matter Eligibility Revision 08, 2017. 
ventor does not create any technical idea with intention, are not considered as a statutory 'invention'. (However, if things in nature such as chemical substances or microorganisms have been isolated artificially from their surroundings, those are creations and considered as a statutory 'invention"' (Part III, Chapter 1 2.1.2 ${ }^{13}$ ) (however, the Opinion cannot accept this view, because a difference of principles and their use has not arisen in isolation. The microbe merely isolated, even in U.S.A. is not a subject (matter) for a patent).

4) Explanation for understanding the Opinion regarding "July 2015 Update Appendix 2: Index of Eligibility Examples"14 for use with" the 2014 Interim Guidance on a Subject Matter Eligibility" in USPTO, is added.

(1) The index of the said guidance is a procedure as follows and determines the eligibility for a patent (a part is shown Table 2).

Step 1: Does it belong to the category (process, machine, manufacture and composite) described in Patent Law Article 101? (if it belongs, it would have eligibility). Step 2: Does it belong to the exception (abstract idea, natural product, etc.), which described in step 2A? (if it does not belong, it would have eligibility). Step 2A (MDC (Markedly Different characteristics) analysis): If it has the "structure", "form", "physical property", "chemical property", "function", or "activity" which are "the remarkably different characteristic" compared with the natural products etc. it does not belong to step 2A (exception) and has eligibility.

(2) The characteristics mentioned in step 2A (MDC analysis) are thought to correspond to 6 factors, and "use of principle" and "ways of use" in the Opinion. That is, "form", "structure", "physical property" and "chemical property" correspond to "shape", "structure", "physical property" and "chemical property", respectively, among 6 factors concerning the appearance and property of an article. However, they do not include "combination of an article" and "transformation of property of material" in 6 factors (it is thought that the technology of IT is included in combination of the article). The "function" and "activity" in this case are considered to correspond to "use of a principle" and "ways of use", respectively. The above is considered appropriate on the grounds that step $2 \mathrm{~A}$ (MDC analysis), including the factors extracted from the physical-object type and material type, follows step 1, corresponding the physical-object invention and material invention.

That is, step 2A (MDC analysis) is equivalent to only juxtaposing (one dimension) the arrangement in two dimensions shown in Table 1 based on the Opinion (An invention is shown as $\mathrm{B}$ and $\mathrm{C}$ parts in the table).

(3) From the above, step 2A (MDC analysis) will be more rational by modifying into two-dimensional display adding a combination of an article and a ${ }^{13} \mathrm{With}$ regard to the examination guidelines of Japan, U.S.A. and EU (E.P.C.), they are expressed formally as follows. Japan: Examination Guidelines for the Patent and Utility Model. U.S.A.: Manual of Patent Examination Procedure (M.P.E.P.). EU (E.P.C.): Guidelines for Examination in the European Patent Office. In this article, the above guidelines are expressed only shortly as "Examination Guidelines" without special notice.

${ }^{14}$ Manual of Patent Examination Procedure (M.P.E.P.) (U.S.A.), July 2015 Update Appendix 2: Index of Eligibility Examples. 
Table 2. Index of eligibility examples.

\begin{tabular}{|c|c|c|c|c|c|c|}
\hline Ex. No. & Source & Title & $\begin{array}{c}\text { Step 1: } \\
\text { Statutory } \\
\text { Category }\end{array}$ & $\begin{array}{l}\text { Step 2A: } \\
\text { Exception }\end{array}$ & $\begin{array}{l}\text { Step 2A: } \\
\text { MDC } \\
\text { Analysis }\end{array}$ & $\begin{array}{c}\text { Step 2B: } \\
\text { Significantly More } \\
\text { Considerations }\end{array}$ \\
\hline$\dot{\cdot} \cdot$ & & & & & & \\
\hline $\begin{array}{l}\dot{9} \\
\dot{.}\end{array}$ & NBP-1 & $\begin{array}{c}\text { Gunpowder } \\
\text { and Fireworks }\end{array}$ & $\begin{array}{l}\text { Composition, } \\
\text { Manufacture }\end{array}$ & $\begin{array}{l}\text { Product of } \\
\text { Nature }\end{array}$ & $\begin{array}{c}\text { Chem/phys } \\
\text { property }\end{array}$ & $\mathrm{n} / \mathrm{a}$ \\
\hline $\begin{array}{l}18 \\
\cdot \\
\cdot\end{array}$ & NBP-10 & Food & Composition & $\begin{array}{l}\text { Product of } \\
\text { Nature }\end{array}$ & $\begin{array}{l}\text { Function/ } \\
\text { activity }\end{array}$ & $\mathrm{n} / \mathrm{a}$ \\
\hline
\end{tabular}

transformation of property of material (if needed, "/" is put in between the terms and makes two-dimensional expression) like the Opinion. This is because two-dimensional arrangement is derived as the essence of an invention like the aforementioned 1 1) 4).

(4) According to the Opinion, unlike the said guidance, at first, a technology and an invention is arranged by step 2A (MDC analysis) corrected as shown above. Next, whether it is an invention or not will be examined by a definition of an invention (including a content of step 2A (exception)). After that, patentability and patenting will be considered. This procedure is the same also in Japanese Patent Law (refer to Figure 1 later).

\subsection{Invention and Patentability in EU (E.P.C.)}

E.P.C. has no regulation about an invention which defines from the positive side of what is regarded as an invention like Japanese Patent Law. It shows the example of what "shall not be regarded as inventions" negatively (Article 52). Thereby, a discovery is not an invention, and a computer program is also not an invention.

And next, as what "patent shall not be granted in respect of....", it shows "plant or animal varieties... method treatment of the human or animal body by surgery or therapy" (Article 53). With regard to this point, although U.S.A. Patent Law ordains positively the subject to be granted as a patent in Article 101, and E.P.C. negatively raises "what a patent shall not be granted in respect of...", there are common points.

Therefore, although an argument about invention and its patentability has so far been made comparing Japanese Patent Law with U.S.A. Patent Law, this is common to an interpretation of E.P.C also.

\subsection{Requirements for Patent}

Although 1) 2) 3) are the composition of Japanese Patent Law (Article 29), the frame-work of the Opinion is the same as it is. Regarding 2) and 3), the Opinion 
determines them according to the identity and the degree of a difference of principles and their use. The degree of the difference is decided based on the difficulty of a prediction by a person ordinarily skilled in the art.

1) An invention that is industrially applicable

Because the Opinion adopts the criterion based on principles and their use, there is no problem if it is fulfilled. The above requirement can be considered in correspondence to the aforementioned U.S.A. Patent Law Article 101 (subject matter) in some points of view.

2) Novelty

It is determined by the identity of principles and their use.

3) Inventive step

(1) Meaning

Japanese Patent Law provides "Where, prior to the filing of the patent application, a person ordinarily skilled in the art of the invention would have been able to easily make the invention based on the prior art, a patent shall not be granted for such an invention" (Article 29, Paragraph 2), wherein non-easiness in conceiving of the invention is adopted as the criterion of inventive step.

On the other hand, U.S.A. Patent Law (35USC Article 103), British Patent Law ((2014) the 3rd, Article 1), German Patent Law ((2013) the 4th, Article 1), and the European Patent Convention (EPC) (Article 56) all provide that when an invention is "obvious", which is expressed in relation to the part corresponding to Japanese Law, it cannot be granted a patent. They adopt the nonobviousness as a criterion of the invention step.

Originally, because a patent should be granted to an inventor's act (invention), non-easiness in conceiving of the invention is thought as more logical than nonobviousness. On the other hand, an act cannot be judged easily, and nonobviousness seems to be more objective which is determined from the object of an act. However, as seen in could-would approach in EU described later, nonobviousness is determined based on teaching from prior arts. Because this is thought of as the motive (cause) of act, it is understood in practice to be similar to non-easiness in conceiving. Also, it is supposed that, in actual operation, the same result is brought (Tokkyo-chō and Shadan-hōjin Hatusumei-kyōkai Ajia Tahiheiyō Kōgyoshoyūken Sentā (APIC), Tsukanaka, T. Coop., 2011).

In this article, non-easiness in conceiving of the invention and nonobviousness of the invention are considered in the same way.

(2) The Opinion

The Opinion makes a determination about the degree (objectivity) of the difference in the principles and their use which is an object of an act (subjectivity). The criterion is whether prediction of the degree of a difference is difficult. The case where prediction is difficult is expressed as "non-easiness of conceiving" or "nonobviousness".

"The abovementioned views except for the Opinion" uses teaching, suggestion, motivation, etc. to the act as the criteria which should be said the motive (cause) of the act, because it is difficult to determine based on just the act itself: 
however, it is indefinite. Although there is also a view in which the problem to be solved in invention should be an object, a problem to be solved is before an invention and cannot be taken further.

In other words, "the views except for the Opinion" think about commonality and difference (hereinafter "commonality/difference") of a claim etc. between the application invention and the prior invention; on the other hand, the Opinion thinks about commonality/difference of principles and their use also which support the claims of both inventions, while investigating one step deeper.

Figuratively speaking, furthermore, when it is difficult to evaluate an act itself, "the views except for the Opinion" think with going back to a motive which is a prior stage of an act (so to speak, upstream), on the other hand, the Opinion think about principles and their use which is an object of an act and is included in a result (so to speak, downstream). It is intelligible that latter one can make more objective determination.

In addition, there is a case of (criminal) negligence as an example in which an existence of subjectivity (fault. violation of a duty of care) is determined from the result of an act (objectivity).

(3) Conclusion

"The views except for the Opinion" make a legal fiction of an evaluation of an inventive step from a motive (subjectivity) of an act; on the other hand, the Opinion makes a legal fiction of an evaluation of an inventive step based on the difference of principles and their use (objectivity).

Because a determination of an inventive step finally reaches subjectivity, to determine it from an objective situation, a legal fiction cannot help being added to it. Regarding this, the Opinion adopts principles and their use which is clearer than a motive of an act. The Opinion seems to be clearer as a criterion.

In addition, the Opinion can consider the direction of quantification of non-easiness in conceiving and nonobviousness by thinking of the degree of difference of principles and their use.

\subsection{Conclusion between the Patent Law of Each Countries and the Opinion Regarding Invention and Patenting}

There is no positive definition about an invention except for Japanese Patent Law.

U.S.A. Patent Law regulates "patentable invention" ("subject matter of an invention", "subject for a patent").

According to a court decision also about an inventor by U.S.A. Patent Law, it can be read that an essence of an invention is "a definite and permanent idea", that is, a principle. EU (E.P.C) exemplifies what "shall not be regarded as an invention". Moreover, it regulates what "shall not be granted as patent" even if it formally corresponds to an invention.

Figure 1 describes the abovementioned all inclusively. Although still more concrete techniques about criterion of an inventive step will be stated on and after 4 , they will be added to the table for showing a whole flow and relation. 


\begin{tabular}{|c|c|c|c|c|c|}
\hline & \multicolumn{2}{|c|}{ invention } & \multicolumn{3}{|c|}{ patenting (obtaining a patent) } \\
\hline & conception & $\begin{array}{r}\text { enbodiment of } \\
\text { conception }\end{array}$ & indentification of object & inventive step & criterion of inventive step \\
\hline $\begin{array}{c}\text { Japanese } \\
\text { Patent } \\
\text { Law }\end{array}$ & $\begin{array}{l}\begin{array}{c}\text { utilizing laws of nature } \\
\text { principle of physics } \\
\text { and chemistry }\end{array} \\
\text { technical }\end{array}$ & $\begin{array}{l}\text { creation } \\
\text { deas }\end{array}$ & & $\begin{array}{l}\text { non-easiness } \\
\text { in conceiving } \\
\text { of invention }\end{array}$ & $\begin{array}{l}\text { - suggestion etc. (court decision) } \\
\text { - consideration of technical field, } \\
\text { problem to be solved, and operation } \\
\text { or function etc. } \\
\text { (court decision) }\end{array}$ \\
\hline $\begin{array}{l}\text { the } \\
\text { Opinion }\end{array}$ & $\begin{array}{l}\text { (to solve the proble } \\
\text { ways of use of } \\
\text { (also called principle }\end{array}$ & $\begin{array}{l}\text { n) } \\
\text { rinciple } \\
\text { and their use) }\end{array}$ & & $\begin{array}{c}\text { non-easiness in } \\
\text { conceiving } \\
\text { of invention } \\
\text { (nonobviousness) }\end{array}$ & \begin{tabular}{|l|l} 
grade of difference of principle and their use & invisible $^{* 4}$ \\
depend of possibility of prediction of difference & (object) \\
-consideration of technical field, problem to be & visible \\
solved, and operation or function etc. & (subject) \\
- consideration of principles and their use about & \\
selection of the cited invention also. & \\
-practical way of use of the opinion: \\
$\begin{array}{l}\text { when suggestion etc. is clear, no need to } \\
\text { examine principles and their use. } \\
\text { when it is difficult, need to examine. }\end{array}$
\end{tabular} \\
\hline $\begin{array}{c}\text { U.S.A } \\
\text { Patent law }\end{array}$ & & & $\begin{array}{l}\text {-invention or discovery of new } \\
\text { and useful process, machine, } \\
\text { manufacture, or composite of } \\
\text { matter } \\
\text {-discovery } * 3 \\
\text { corresponds to use (of principle) } \\
\text { or especially for way of use } \\
\text {-invention has a phase of model, } \\
\text { and discovery has a phase of } \\
\text { conception }\end{array}$ & nonobviousness & $\begin{array}{l}\text { TSM } \\
\text { (teaching, suggestion, motivation) }\end{array}$ \\
\hline \multirow[t]{2}{*}{$\begin{array}{l}\mathrm{EU}(\mathrm{EPC}) \\
\quad(\mathrm{PCT})\end{array}$} & $\begin{array}{l}\text { descovery etc. wh } \\
\text { cannnot be regaro } \\
\text { invention is showr } \\
\text { example. }\end{array}$ & $\begin{array}{l}\text { ich } \\
\text { ed as } \\
\text { as }\end{array}$ & $\begin{array}{l}\text { plant or animal varieties } \cdots \\
\text { method for treatment of } \\
\text { the human or animal body } \\
\text { to which patent shall not } \\
\text { be granted is provided }\end{array}$ & nonobviousness & $\left\{\begin{array}{l}\text { problem-solution approach } \\
\left\{\begin{array}{l}\text { objective technical approach } \\
\text { Could-would approach } \\
\begin{array}{l}\text { (existence or non-existence of } \\
\text { teaching which "would") }\end{array}\end{array}\right. \\
\end{array}\right.$ \\
\hline & $\begin{array}{l}\text { inventor: person who } \mathrm{n} \\
\text { person who made } \\
\text { following conception }\end{array}$ & ade, invention & & & \\
\hline $\begin{array}{r}\text { court decision } \\
\text { in U.S.A }\end{array}$ & $\begin{array}{l}\text { definite and } \\
\text { permanent } \\
\text { idea }\end{array}$ & & & & \\
\hline court decision & "the heart" & & & & \\
\hline $\begin{array}{r}\text { court decision } \\
\text { in Japan }\end{array}$ & $\begin{array}{l}\text { technical } \\
\text { knowledge }\end{array}$ & & & & \\
\hline $\begin{array}{l}\text { court decision } \\
\text { in Germany }\end{array}$ & $\begin{array}{l}\text { creative contribution } \\
\text { to invention } * 5\end{array}$ & & & & \\
\hline the Opinion & $\begin{array}{l}\text { conception based } \\
\text { on a principle }\end{array}$ & $\begin{array}{l}\text { establishment } \\
\text { of a model }\end{array}$ & & & \\
\hline
\end{tabular}

Figure 1. Comparison between patent law of each country and the Opinion about an invention and patenting. ${ }^{\star} 1$ This is a substantial meaning of invention by the Opinion; ${ }^{\star} 2$ Examination Guidelines in Japan raises the relation of a technical field, the similarity of a problem to be solved, and the similarity of operations or functions as contents of motivation. Because these are intelligible because of including a subjective and visible phase in some cases, taking into consideration an orientation for determination of a difference of principles and their use, will bring facilities which can limit a range of determination. For details, please refer to (4.6) 2); $* 3$ Although a machine is a thing, since it produces manufacture and a composite using a process, it seems to be placed between a process and a manufacture/ composite. An invention has a phase of conception (idea) and a phase of its embodiment (creation, establishment of model). The discovery seems to have a strong phase of conception, and the invention seems to have a strong phase of embodiment of conception. Even if the discovery is made, being granted as a patent should be concerning the composition of matter, process, etc; ${ }^{*} 4$ It is considered that the Opinion makes determination fundamentally based on objectivity and pays attention to the subjectivity for an orientation of determination; on the other hand, EU focuses on subjectivity fundamentally and thinks objectivity additionally for an orientation of determination. See (4.7) for reference; 5 "Creative contribution" (BGH, Urteil vom 16.9. 2003-XZR142/01) described in a court decision of Germany can also be called as tautology. 


\section{Appropriateness of Grasp of Invention Based on the Opinion and its Practical Use for Making a Norm}

According to what has been stated until now, it turned out that a unified interpretation and determination could be made through the concept of an invention, finding an inventor, the subject (matter) for a patent, requirements for a patent (industrial applicability, novelty, inventive step) by grasping invention as principles and their use based on the Opinion, especially Opinion 2. According to this, it is understood that grasping of the invention based on the Opinion is more appropriate than that based on conventional views except for the Opinion.

Although it is not mentioned in this article, the application of the Opinion is still more useful also in the interpretation (objectivity) of a claim (for example, a doctrine of equivalents).

As mentioned above, the application of the Opinion is useful for the problem in relation to the essence of invention in patent system etc., such as the concept of an invention, patenting and an interpretation of patented invention. It can be said that this is a natural result, because, the principles and their use, which the Opinion is based on, are the essence of an invention.

The example which practically occurred is arranged and typified, and it is taken up as the criterion in the examination guidelines in each country. Because it is useful for the Opinion to arrange and abstract the fact about invention, and to make a norm from it, it seems that a more logical and clear criterion can be established by using the Opinion.

It seems that examination practice, including the examination guidelines of each country, now operates for the maintenance and the interpretation, so to speak, to cope with the actually occurring problem. In parallel with these practical efforts, it seems that the examination from a fundamental point based on the Opinion is effective so that it can cope more rationally and quickly.

In this article, after the following 4, the Opinion is concretely applied to the determination of the inventive step, and the problem of the examination guidelines in each country is clarified. Simultaneously, in this article, although the principles and their use have been considered in the whole technology and invention so far, the elucidation about the principles and their use as a whole and as a part in the process of determination of the inventive step is also made.

\section{Framework and Procedures for Determination of the Inventive step}

In this section, discussion is made, with regard to the base of the framework and procedure for inventive step, in Japan, U.S.A., EU and the Opinion.

\subsection{Framework for Determination of the Inventive Step}

Framework for determination of the inventive step is common to Japan, U.S.A. and EU as follows.

1) Finding of invention (application invention) which is going to obtain a patent. 
Understanding the feature of the application invention is included.

2) Selection of the cited invention (the prior art).

The prior art which is the closest (similar) to the application invention is selected as the cited invention. Generally, similarity of elements of an invention would be the most important criterion to determine whether it is close or not. In addition, in Examination Guidelines in Japan, "the examiner selects generally the primary cited invention which is same as or close to the claimed invention (Author's note: application invention) from the aspect of technical field or problem to be solved" (Part III Chapter 2 Section 23.3 (2)). This is one kind of manifestation of being close to the application invention.

3) Finding of the points of identity and difference between the cited invention and the application invention.

However, the problem-solution approach in EU includes the point of difference in the contents of the objective technical problem which is established.

4) Considering the state of the art, determination of whether a person skilled in the art can easily reach the application invention starting from a prior art.

\subsection{The Procedure of a Determination-Common Parts}

The parts of above 1) and 2) are common also as a procedure of concrete determination in Japan, U.S.A. and EU. The secondary cited invention other than the primary cited invention is selected and applied to the primary cited invention in many cases. There are many cases of procedure of determination of whether the application invention can be reached with the above application. Common general knowledge of engineering and well-known art is also taken into consideration.

Regarding 3), only problem-solution approach adopted in EU differs in preparing the objective technical problem prior to the determination of 4), and there are some differences in a concrete method and procedure of 4) in Japan, U.S.A. and EU.

\subsection{Criterion of Determination-Different parts 1): Objective Technical Problem to Be Solved in EU}

The examination guidelines in EU states as follows. "One studies the application, the closest prior art and the difference (also called the distinguishing feature(s)'of the claimed invention) in terms of features (either structural or functional) between the claimed invention and the closest prior art, identifies the technical effect resulting from the distinguishing features, and then formulates the technical problem" (E.P.C. Chapter VII inventive step 5.2). Strait to the point, it is established from the difference of the elements between the application invention and the cited invention, and the technical effects (Author's notes: they are generated from principles and their use) of the application invention.

(1) Meaning of "objective"

It means that problems to be solved are established in objective contrast with the closest prior art to the claimed invention. Therefore, it may not be "the 
problems to be solved described in the application documents at the beginning."

(2) Meaning of "technical"

It means that "technical effects which produce the distinguishing features" is confirmed, and the problems to be solved are established in accordance with it. The technical effect by the distinguishing features is determined by comparing the content of the specification with the closest prior art. Therefore, it is usually supposed that this objective technical problem is considerably relevant to "the problem to be solved described in the application documents at the beginning" effectively (Chou, 2016).

The above mentioned used the literature of footnote 4.1 as a significant reference.

(3) The meaning of establishment (so to speak, reconstruction) of the objective technical problem in addition with "the problem to be solved described in the application documents at the beginning".

In the next step of procedure for determination of "whether the application invention can be arrived starting from the prior art," that is, Could-would approach, a subjective determination is made regarding an act based on a criterion of whether there is any teaching in the prior art which is "not simply could, but would". Then, standing on the starting point for determination, the objective technical problem can be understood for the sake of giving objective orientation to determination.

(4) The objective technical problem must not contain the indices (Author's notes: solution means etc.) of solution. It is for not producing an ex-post view (hindsight).

(5) At present, with regard to "Problem-and-Solution approach"15 adopted by EU, P.C.T. also introduces it. U.K. follows it and Germany harmonizes it. U.S.A. is considered to be using it as a major approach. Japan trends to be in the direction of weighing it.

Specifically, this can be understood because of tendency to consent to establishment of the objective technical problem.

(6) Although meaning of establishment of the objective technical problem is as abovementioned, it seems that any issue will not occur especially in examination if the suitable prior art is pointed out in the application documents and the "problem to be solved" based on it is indicated, in actual application.

\subsection{Criterion of Determination-Different Parts 2): The View in Each Country Related to the Attainment to the Application Invention from the Prior Art}
1) Japan
(1) Court decision

a) "(Inventive step) may be determined based on whether it was easy for a person ordinarily skilled in the art to reach the features of the claimed invention ${ }^{15}$ Guideline for Examination in the European Patent Office, November 2015 edition, Part Chapter VII/5, Problem-and-Solution approach. 
(application invention) (the structure that constitutes the difference from the cited invention) starting from the cited invention... In order to determine that the claimed invention could have been easily conceived, ... rather it is necessary that there are suggestions and so on showing the fact that efforts must have been made to reach the features" (IP High Court decision on 25 March $2009^{16}$ ).

b) "The conclusion must be drawn, by comparing the claimed invention with selected prior arts to specify the structure (constitution) of the claimed invention different from the prior arts, and examining whether it was easy for a person ordinarily skilled in the art, on the condition of the state of the art at the time of application, to arrive at the structure of the art at the time of application, to arrive at the structure of the said invention in relation to the differences. In this examination, the following matters should be considered as a whole: the degree of relation in the technical field between the claimed invention and the prior arts, the commonality in the problem to be solved, and the function/effect, and so on" (IP High Court decision on 31 January $2011^{17}$ ).

In the above, the degree of relation in the technical field, the commonality in the problem to be solved, and the function/effect are the factors to accept the motivation which deny the inventive step with the application of the secondary cited invention to the primary cited invention in the Examination Guidelines in Japan, as can be seen in Figure 3 later.

(2) Examination guidelines

Although it will be stated in detail in (5.1) 1) later, the inventive step is decided according to whether the reasoning, which starts from a prior art (the cited invention) and easily reaches to the application invention, is possible or not.

The reasoning is carried out by evaluating the following factors.

As the factor of denial to inventive step, motivation for applying the secondary cited invention to the primary cited invention, design variation from the primary cited invention, and mere aggregation of prior art are mentioned. As the factor of affirmation for inventive step, the advantageous effects (exceed what is predictable) of the claimed invention and obstructive factors, for example, the factor which is contrary to the purpose of the primary cited invention to apply the secondary cited invention to the primary cited invention, are mentioned.

As stated, motivation and the obstructive factors are considered in substantially the same way relating to whether an application invention can be reached from a prior art (cited invention).

2) U.S.A.

(1) TSM test

To say that the difference between the subject matter of application invention and a prior art is obvious for a person skilled in the art, existence of the description about "teaching", "suggestion" or "motivation" of the combination specified

${ }^{16}$ Sakai Kagaku Kōgyō K.K. v. Kawakami Sangyō K.K (2009) “Collection of Decision of Intellectual Property Cases" Supreme Court of Japan Website.

${ }^{17}$ X v. Debiofāmu Esu Ā (2009) “Collective of Decision of Intellectual Property Cases” Supreme Court of Japan Website. 
by the claim must be shown.

(2) Court decision in Graham case ${ }^{18}$.

It stated the Graham test including TSM test:

In Graham Test, “...the obviousness or nonobviousness of the subject matter is determined. Such secondary considerations as commercial success, long felt but unsolved needs, failure of others, etc., might be utilized to give light to the circumstances".

(3) Court decision in KSR case $\mathrm{e}^{19}$

"Seeking to resolve the question of obviousness..., the Court of Appeals for the Federal Circuit has employed an approach referred to by the parties as the 'teaching, suggestion, or motivation' test (TSM test), under which a patent claim is only proved obvious if 'some motivation or suggestion to combine the prior art teachings' can be found in the prior art, the nature of the problem, or the knowledge of a person having ordinary skill in the art."

However, "(Based on the TSM test,) the obviousness analysis cannot be confined by a formalistic conception of the words teaching, suggestion, and motivation, or by overemphasis on the importance of published articles and the explicit content of issued patents." "Rigid preventative rules that deny fact finders recourse to common sense, however, are neither necessary under our case law nor consistent with it".

In fact, the said court decision stated that TSM test should be applied, not being strict and considering common general knowledge of engineering etc.

(4) Examination Guidelines

"Examination Guidelines for Determining Obviousness Under 35 U.S.C. 103 in view of the Supreme Court Decision in KSR International Co. v. Teleflex Inc." was published on October 10, $2010^{20}$ (also (4.5) 5),(6.1) 2) ref.).

The new criterion about obviousness is explained with the following examples.

a) Combining prior art elements according to known methods to yield predictable results;

b) Simple substitution of one known element for another to obtain predictable results;

c) Use of known technique to improve similar devices (methods, or products) in the same way;

d) Applying a known technique to a known device (method, or product) ready for improvement to yield predictable results;

e) "Obvious to try" - choosing from a finite number of identified, predictable solutions, with a reasonable expectation of success;

f) Known work in one field of endeavor may prompt variations of it for use in either the same field or a different one based on design incentives or other market forces if the variations would have been predictable to one of ordinary skill ${ }^{18}$ Graham v. John Deere Co., 383U.S.1, 148 USP 459 (1966).

${ }^{19}$ KSR International Co. v. Telefax Inc. 550 U.S. 398 (2007) (30 April 2007).

${ }^{20}$ https://www.uspto.gov/sites/default/files/web/offices/com/sol/notices/72fr57526.pdf. 
in the art;

g) Some teaching, suggestion, or motivation in the prior art that would have led one of ordinary skill to modify the prior art reference or to combine prior art reference teachings to arrive at the claimed invention.

3) $\mathrm{EU}$

(1) Could-would approach

Whether the application invention is obvious for the person skilled in the art starting from the objective technical problem to be solved and cited invention mentioned in 1) is determined as follows.

"...is whether there is any teaching in the prior art as a whole that would (not simply could, but would) have prompted the skilled person, faced with the objective technical problem, to modify or adapt the closest prior art while taking account of that teaching, thereby arriving at something falling within the terms of the claims, and thus achieving what the invention achieves" "Even an implicit prompting or implicitly recognizable incentive is sufficient to show that the skilled person would have combined the elements from the prior art" (Chapter VII 5.3).

(2) The example of "Could-would" which appeared in the court decision ${ }^{21}$ will be mentioned.

"If, in a chemical case, the inventor shows that he reacted A with B to obtain a product which has some extremely desirable properties, that will not be rendered obvious simply by showing that a man in the art knew of A and B and would have realized that they were capable of reacting with one another. It would need to be proved that he would have bothered doing it."

(3) The problem to be solved is originally the purpose of invention, and the objective technical problem is the orientation which looks at an (invention) act and carries out a legal fiction that an applicant ought to have performed the invention act for such the purpose, as mentioned above (4.3) 1) (3). It does not necessarily correspond to the problem to be solved which the applicant actually intended ((4.3) 1) (1)). That is presumed one of the legal fictions which determine the applicant's act.

In this meaning, it is considered that the problem-solution approach to determine the inventive step includes two legal fictions, which are the establishment of the objective technical problem and could-would approach (a legal fiction to determine the act from the motive of an act (teaching etc.)).

In addition, although explained in detail in (4.7) and (6.2) 1) (1), establishment of an objective technical problem also has an issue that it easily falls into the hindsight because of taking into consideration the effect of application too (see (4.3) 1)).

\subsection{The Conclusion of the Different Portion of Determination Criterion in Japan, U.S.A. and EU}

Japan adopts suggestion, reasoning and motivation; U.S.A. adopts teaching,

${ }^{21}$ Hoechest Cellenese Corp. v. BP Chemicals ltd. (1997) EWHC 370 (Pat) (6 Feb. 1997). 
suggestion and motivation; and could-would approach in EU concretely adopts teaching and motivation.

With regard to the above wording, "teaching" seems to be the strongest in a legal fiction which evaluate an act from its motive because this is related with the relation between a prior engineer and an applicant (doer), "motivation" has a meaning which figures a doer's subjectivity, and "suggestion" has an implication which is received from the expression of the act being made. All of them show the motive of the act and can be called the legal fiction which evaluates the act. Although "reasoning" seems to show an atmosphere on necessity, it could be the said as tautology (synonymous to repetition).

After all, all are common in wording, and are common at the point of evaluation from the motive of the act ("suggestion" has an objective atmosphere, is it the most appropriate?).

In addition, the criterion for determination of the inventive step in P.C.T. (Patent Cooperation Treaty) is common in EU.

\subsection{The Determination Procedure and Criterion in the Opinion}

1) In the Opinion, the framework for determination ((4.1) above) and the common portions of the determination procedure ((4.2) above) of the inventive step are the same as those in Japan, U.S.A. and EU.

However, consideration of the following point is required.

(1) Finding of the application invention

Application invention is identified positioning into two-dimensional arrangement of the technology and invention by the Opinion. Investigation of principles and their use is made especially. The features of the application invention will be understood, and attention will be paid to the principles and their use as a whole.

(2) Selection of the cited invention

The principles and their use which can be read from the constitution of the application invention are taken into consideration in the selection of the cited invention. In the main cited invention (primary cited invention), the principles and their use as a whole will be taken mainly.

(3) Point of identity and point of difference. Selection of other cited inventions

Although the point of differences between the primary cited invention and the application invention are fundamentally based on the difference of the constitution of both invention, the difference of the principles and their use is also considered together with it. The point of differences is considered, focusing on the principles and their use as a part. The point of identities could be considered, focusing on the principles and their use as a whole.

In relation to the above point of difference, although other cited inventions (the secondary cited invention) which have its constitution may be selected in some cases, the principles and their use supporting the constitution can be considered. In this case, principles and their use as a part are focused on considera- 
tion.

2) Comparison of the principles and their use between the application invention and a prior art

(1) The thinking form of "whether the application invention can be reached starting from the prior art" is not necessarily taken. The principle and their use between the application invention and a prior art are compared directly. However, it is possible to determine the difference in the principles and their use according to the above thinking form, for the sake of thinking and convenience of explanation.

In addition, because a problem to be solved (the purpose of invention) is prior to an invention, this view is not directly evaluated to the commonality/difference (commonality and difference) of the principles and their use of the application invention and the cited invention.

(2) Practically, in many cases, it will be considered that the primary cited invention and the secondary cited invention are selected from a prior art, and whether the application invention may be reached with applying the latter invention to the former invention. Regarding this, although the primary cited invention is focused on the principles and their use as a whole and the secondary cited invention is focused on the principles and their use as a part, collectively, the effect as a whole will be considered. Therefore, it will be said that the above determination is made based on the principles and their use as a whole, taking into consideration the important principles and their use as a part.

(3) And now, when determining the inventive step based on the commonality/difference of the principles and their use of the application invention and the cited invention by the Opinion, it seems convenient and rational to limit (narrow) the range of determination from the following viewpoints.

That is, it means that examining the commonality/difference of the principles and their use, the effect of an invention (a), operation or function (b), and problem to be solved (c) can be referred to as the orientation to determine the inventive step. The reason is as follows.

First, it is hard to feel the principles and their use and their difference by the five sensory organs, and they are derived out by thinking. Whereby, derivation is often difficult and this is a fault. On the other hand, an effect, and an operation or a function is sensitive to the five sensory organs, and they are visible in some cases, because of seeing invention from appearance (phenomenon). Because the problem to be solved is described, the contents are still more intelligible.

Second, because the above (a), (b) and (c) are used as factors for determining the inventive step in Examination Guidelines in Japan (p. 25 later, Figure 3 ref.), it is easy to deal with them in practice. As a result, using them as the orientation which evaluates the commonality/difference of the principles and their use by the Opinion shall make it easier to use them as relevant to practice.

3) The determination criterion of the inventive step

The inventive step is determined by the criterion whether a person skilled in the art can easily predict the difference, after the finding of the degree of the said 
difference of the principles and their use between the application invention and the prior art is made.

When the above prediction is easy, it could be understood as "it can be reached easily" in relation to views except for the Opinion (non-existence of the inventive step).

4) Amendment of the principles and their use. Change of the cited invention

With regard to the abovementioned principles and their use of the application invention, the primary cited invention, and the secondary cited invention, the elucidation of the principles and their uses will progress in clarification of the point of the difference, and in selection of the secondary cited invention, or in the determination whether the application invention can be reached from the prior art. As a result, it is considered that more exact principles and use will become clear. In this case, amendment of the principles and their use must be made flexibly.

On the contrary, in relation to the principles and their use of the application invention, if selection of the primary and secondary cited invention proves unsuitable, the cited invention must be changed.

5) Although the examples raised in the examination guidelines of U.S.A. of the abovementioned (4.4) 2) (4) seem to have been extracted out of accumulation of a court decision, they can be considered corresponding to 6 factors that are a criterion which abstracts the technology explained in the Opinion.

That is to say, it is considered that the above example A) corresponds to combination of object, B) corresponds to structure of article or chemical property of material. C) D) E) correspond to structure of article, F) corresponds to shape of article, G) corresponds to structure of article or chemical property of material, respectively.

According to the abovementioned, in addition to 7 raised as examples in the examination guidelines in U.S.A., it can be considered that there are some examples which show non-existence of inventive step based on 6 factors and their combination.

That is, because the Opinion includes the stage which makes arrangement and abstraction of technology and invention, by means of applying the Opinion, the arrangement of facts, making the abstraction and the norm of them, and besides, finding out the example which has leaked, and prediction of the example which may be caused, can be conceived.

\subsection{Comparison of Japan, U.S.A., EU and the Opinion}

Comparison of the procedure of determination in Japan, U.S.A., E.U., and the Opinion is shown in Figure 2.

Object for determination in case A and case B is an act. That of case $\mathrm{C}$ is a fact. Because determination based on the act itself is difficult, motive of an act will be treated. Whether "teaching" exists or not, conducting the cited invention to the application invention act in could-would approach, is a kind of example. This would be indefinite still. In addition, generally, because a problem to be 
A. Japan, U.S.A.

$\begin{array}{cc}\text { Premise } & \text { Determination }\end{array}$

Japan: easiness in

$\left.\begin{array}{l}\text { application invention: constitution } \\ \text { cited invention: constitution }\end{array}\right]$ difference

B. EU

objective technical problem

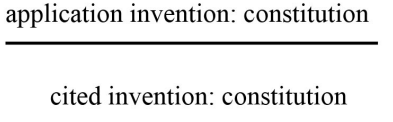

difference/

effect(application invention)

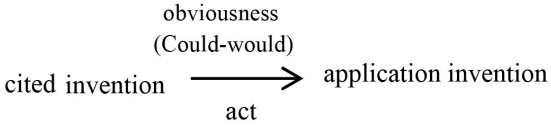

$$
\begin{gathered}
\text { cited invention } \stackrel{\text { inventive step }}{\longrightarrow} \text { application invention } \\
\begin{array}{l}
\text { commonality/difference of } \\
\text { principles and their uses (fact) }
\end{array}
\end{gathered}
$$

Figure 2. Procedure of attainment to application invention from cited invention of each country and the Opinion Summarizing the above, it can state the following.

solved is prior to invention, it is not appropriate to use it with significant concern to determine the inventive step.

Difference between case A and case B consists in that B uses the objective technical problem to be solved set up by the examiner, including "the effect of the application invention" etc. as the orientation for determination of obviousness. Because an effect is an objective fact, it is considered that case B has an intention to objectify the determination of obviousness based on the effect. Incidentally, because an effect is derived from the principles and their use, an effect serves as the important grounds which extract the principles and their use from an invention.

In case $\mathrm{C}$, originally, because comparison of application invention and cited invention is sufficient to determine the non-obviousness (inventive step), the commonality/difference of the principles and their use which are essences of both inventions is adopted directly. Moreover, because the principles and their use are abstracted from an effect etc., it is suitable for comparison and determination of technology.

Although case B seems to try to more clarify the determination of case A, case $\mathrm{C}$ intends to advance it one more step and can be said that it determines the inventive step based on the comparison of the objective fact.

Moreover, though taking a direction to determine the inventive step, because case $B$ uses the effect of application invention for the objective technical problem 
to be solved, there is a possibility of falling into hindsight. On the contrary, because case $\mathrm{C}$ compares the commonality/difference of the principles and their use between the application invention and the cited invention, there is less possibility of falling into hindsight.

In addition, it is the same as case B that P.C.T. adopts the objective technical problem to be solved as a premise.

\section{Concrete Relation between the Examination Guidelines about the Inventive Step and the Principles and their Use in the Opinion-With Attention to Obstructive Factors in Particular and Also the Prevention of Hindsight}

In this section, with regard to the examination guidelines about inventive step, discussion is made in the actual example, applying the principles and their use in the Opinion. In this Section 5, discussion is mainly made regarding the examination guidelines and court decision in Japan, and in the next Section 6, regarding the relation with those of U.S.A. and EU.

In determination of the inventive step, "obstructive factors" relating to the interpretation of the contents of the invention and "hindsight" which is the viewpoint to look at the invention, become problematic. Hindsight is ex-post decision (p. 39 later ref.), and this harmful result must be prevented. Its prevention is only abbreviated also to "hindsight" in this article.

\subsection{Examination Guidelines in Japan}

The inventive step will be considered with a focus on the case caused most practically of whether the application invention can be reached by applying the second cited invention to the primary cited invention of the prior art (the inventive step is denied in this case).

Discussion will be made based on Examination Guidelines in Japan. This is because dividing into inventive step denial factors and inventive step affirmation factors and progressing determination by the examination guideline, is based on the contents of the invention (the principles and their use of a plus direction and a minus direction, according to the analysis based on the Opinion which will be mentioned below (5.3) 2) 4)) and is rational. This way is not shown clearly in Examination Guidelines of U.S.A and E U. The upper factors are shown in Figure 3.

1) "The examiner determines whether it is possible to reason that a person skilled in the art would easily arrive at the claimed invention from the primary prior art by the following steps (1) to (4) (Examination Guidelines Part III Chapter 2 Section 2 Inventive Step 3).

(1) The examiner determines whether or not the reasoning is possible based on the various factors in support of the non-existence of an inventive step for the differences between the claimed invention and the primary prior art by adopting other pieces of prior art (secondary prior art) or considering the common general knowledge. 


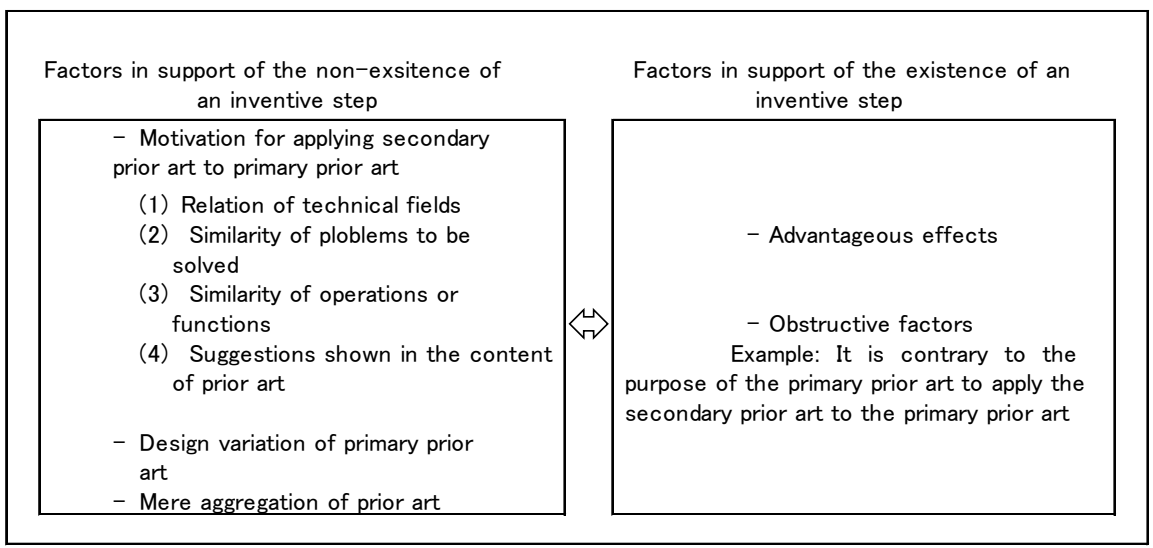

Figure 3. Main factors for reasoning.

(2) If the examiner determines that the reasoning is impossible based on the above step (1), the examiner determines that the claimed invention involves an inventive step.

(3) If the examiner determines that the reasoning is possible based on the above step (1), the examiner determines whether the reasoning is possible by comprehensively assessing various factors which includes factors in support of the existence of an inventive step.

(4) If the examiner determines that the reasoning is impossible based on the above step (3), the examiner determines that the claimed invention involves an inventive step.

If the examiner determines that the reasoning is possible based on the above step (3), the examiner determines that the claimed invention does not involve an inventive step."

2) Obstructive factor

Examination Guidelines in Japan give the following examples of obstructive factor that supports the existence of an inventive step (Part III Chapter 2 Section 2 3.2.2). "(1) The secondary prior art applied to the primary prior art cannot achieve the purpose of the primary prior art (described in Figure 3). (2) The secondary prior art applied to the primary prior art cannot adequately function. (3) The secondary prior art which is considered to be excluded from application and unable to be adopted by the primary prior art. (4) The secondary prior art which a person skilled in the art would not apply due to a publication disclosing that the secondary prior art is inferior to the other embodiment in respect of operations and effects of the prior art."

\subsection{Relation between the Above Factors and the Principles and Their Use as a Whole and as a Part Based on the Opinion}

The denial factors and affirmative factors to determine the inventive step in Examination Guidelines in Japan shown in Figure 3 will be considered aiming at the technological clarification of its actual state by applying the principle as a whole and as a part, especially the principle as a part. 
The very outline of the relation between the above factors and the principles and their use as a whole and a part to which the above factors pay their attention is considered as follows (Table 3 ).

From the above, it is considered that the denial factors of the inventive step, such as motivation, is related to the principles and their use as a whole, and the obstructive factors being main inventive step affirmation are related to the principles and their use as a part. In addition, it seems that principle as a whole is more related with "principle" and "use of principle", and principle as a part is more related with "ways of use".

\subsection{Relation between the above Factors and the Principles and Their Use as a Whole and as a Part Based on the Opinion}

The important principle as a part which has an important effect for the existence or non-existence of the inventive step is considered technologically concretely.

1) The examiner selects the primary cited invention $A+B$ and the secondary cited invention $C$ mainly from appearance about the application invention $\mathrm{A}+\mathrm{B}+\mathrm{C}$ based on the constitution (case of the combination of $\mathrm{A}+\mathrm{B}$ and $\mathrm{C}$ ).

The principle (whole) of the primary cited invention $\mathrm{A}+\mathrm{B}$ is assumed to be $\alpha$, and the principle (whole) of the secondary invention $C$ is assumed to be $\beta$.

First, in the above, if the application invention $\mathrm{A}+\mathrm{B}+\mathrm{C}$ is assumed that $\mathrm{C}$ has a correlated action to $\mathrm{A}+\mathrm{B}, \mathrm{A}$ or $\mathrm{B}$, it can admit of examination whether application of different secondary cited invention $C$ may be considered to the primary cited invention $\mathrm{A}+\mathrm{B}$ formally according to "a theory of dividing invention into elements". It would be necessary to take into consideration substantially the existence or non-existence, and the degree of the above correlation action. Depending on the strength of correlation, it would be said that a selection of the secondary cited invention is unsuitable.

2) Next, consider the easiness of the combination of the secondary cited invention $\mathrm{C}$ with the primary cited invention $\mathrm{A}+\mathrm{B}$ from a viewpoint of a principle.

(1) If the principle of the application invention is $(\alpha+\beta)$ which consists of $\alpha$ and $\beta$ as in (a), (b) and (c) shown in Figure 4 above, the inventive step would not be accepted.

(2) On the other hand, (d), (e) and (f) are considered as follows.

a) $\gamma$ is the principle which the examiner could not found, and it is unclear whether it has been included in $C$ apart from $\beta$, or whether it has been produced by correlation with $\mathrm{A}+\mathrm{B}$ and $\mathrm{C}$. In the above, it is assumed that $\gamma$ would be included in C.

Generally, $\gamma$ produces a new effect as a principle as a part (the plus effect). However, on the other hand, decrease of the effect of $\alpha \beta$ (becoming $\alpha^{\prime}$ and $\beta$ ) may be produced. However, for the inventive step to be accepted, the effect and the utility must increase in its entirety.

b) $\delta$ in (f) (the obstructive factors) can be considered to express one type of $\gamma$. Therefore, many $\delta$ s are the principles as a part. That is, although $\delta$ produces 
Table 3. The denial and affirmative factors of the inventive step, and the principles and their use as a whole and a part.

\begin{tabular}{|c|c|c|c|}
\hline & Examination guidelines & $\begin{array}{l}\text { Principles and their use to } \\
\text { be focused }\end{array}$ & $\begin{array}{c}\text { Relation with "principle", "use of principle" } \\
\text { and "ways of use" }\end{array}$ \\
\hline \multirow{3}{*}{ Inventive step denial } & motivation & whole & principle and use of principle \\
\hline & design variation & part and whole & ways of use. principle and use of principle \\
\hline & aggregation & whole & principle and use of principle \\
\hline \multirow{2}{*}{ Inventive step affirmation } & advantageous effects & whole & principle and use of principle \\
\hline & obstructive factors & part & ways of use \\
\hline
\end{tabular}

\begin{tabular}{|c|c|c|c|c|c|c|}
\hline & & $\begin{array}{l}\text { examination } \\
\text { guidelines }\end{array}$ & \begin{tabular}{|} 
primary cited \\
invention \\
$\mathrm{A}+\mathrm{B}$
\end{tabular} & $\begin{array}{l}\text { secondary cited } \\
\text { invention C }\end{array}$ & \multicolumn{2}{|c|}{$\begin{array}{l}\text { application invention } \\
\qquad \mathrm{A}+\mathrm{B}+\mathrm{C}\end{array}$} \\
\hline \multirow{3}{*}{$\begin{array}{l}\text { non-existence of } \\
\text { inventive step }\end{array}$} & (a) & $\begin{array}{l}\text { Motivation is } \\
\text { possible }\end{array}$ & $(\alpha)$ & $(\beta)$ & \multirow{3}{*}{$-(\alpha+\beta)$} & \\
\hline & (b) & design matter & $(\alpha)$ & $(\beta)$ & & \\
\hline & (c) & mere aggregation & $(\alpha)$ & $(\beta)$ & & \\
\hline \multirow{3}{*}{$\begin{array}{l}\text { Existence of } \\
\text { inventive step }\end{array}$} & (d) & $\begin{array}{l}\text { Motivation is } \\
\text { impossible }\end{array}$ & $(\alpha)$ & $(\beta+\gamma)$ & \multirow{2}{*}{\multicolumn{2}{|c|}{$\begin{array}{ll}(\alpha+\beta+\gamma) & \gamma: \text { denial of motivation } \\
& \text { producing advantageous effects, } \\
\left(\alpha^{\prime}+\beta^{\prime}+\gamma\right) & \text { however } \alpha \text { and } \beta \text { can be reduced } \\
\left(\alpha^{\prime}<\alpha, \quad \beta^{\prime}<\beta\right) & \text { how }\end{array}$}} \\
\hline & (e) & $\begin{array}{l}\text { advantageous } \\
\text { effects }\end{array}$ & $(\alpha)$ & $(\beta+\gamma)$ & & \\
\hline & (f) & $\begin{array}{l}\text { existence of } \\
\text { obstructive factors }\end{array}$ & $(\alpha)$ & $(\beta+\delta)$ & $\begin{array}{l}\left(\alpha^{\prime \prime}+\beta+\delta\right) \\
(\alpha "<<\alpha)\end{array}$ & $\delta: \alpha$ is reduced greatly (obstruction) \\
\hline
\end{tabular}

Figure 4. Factors for denial or affirmation of inventive step, and principle of primary and secondary cited invention.

new effects, they change $\alpha$ to $\alpha$ ", of which effect is greatly reduced than $\alpha$ (the minus direction).

Consequently, according to the Opinion, it will be possible to determine the inventive step of the application invention by considering the character (the plus and minus direction) and the degree of $\gamma$. If $\gamma$ is large, the inventive step will be accepted.

There is no need to say that the obstructive factors are types which are easy to accept, such as an application of the second cited invention is contrary to the purpose of the primary cited invention from the person of claiming for affirmation of the inventive step, consequently, it would be a practically useful point of view to ask for $\gamma(\delta)$ paying attention to this.

c) With regard to the obstructive factors, although the examples mentioned in (5.1) 2) are described, it is considered that more logical typification (to be divided into some types) can be made by analyzing the principles and their use as a part about decreases of the utility (effects) in the invention as a whole.

3) Next, the case of replacement will be considered as the applied use of the above example.

Although, there are many practical cases where the constitution of the primary cited invention is $\mathrm{A}+\mathrm{B}+\mathrm{D}$ and that of the secondary cited invention is $\mathrm{C}$. That 
is to say, whether or not replacing D with $\mathrm{C}$ can be conceived easily.

In this case, for example, the principle $\alpha$ of the primary cited invention is considered as the contribution $\alpha_{1}$ by the elements $\mathrm{A}+\mathrm{B}$ and the contribution $\alpha_{2}$ by the element $\mathrm{D}$. Then consideration of the easiness of replacing $\alpha_{2}$ with $\beta$ based on the similarity of $\alpha_{2}$ and the principle $\beta$ of the secondary cited invention as the subject of determination will come to be made by using logic like above 2).

4) The principle in the direction increasing an effect and the principle in the direction reducing an effect.

As mentioned above (5.3) 2), among principles and their use, there are what contributes to the plus direction which increases the intended effect (raising a utility) and what contributes to the minus direction which reduces an effect (preventing an effect). Also, it can be considered that they have degrees (the direction of quantification). It is considered that principles and their use of the minus direction are mostly generated especially in the material technology/engineering and invention.

To explain the assertion about an inventive step using principles and their use, it is considered that more distinct understanding of the above point is effective.

5) Regarding obstructive factors, because the Opinion has only to determine the objective effect (utility) generated by the principles and their use, there is no need to carry out subjective determination, such as whether it is contrary to the purpose which was described in the examination guidelines (5.1) 2) before.

About this point, the same criticism can be approved in U.S. Patent Law, because it seems that obstructive factors are determined by a skilled person's act (subjectivity) ((6.1) 3) i)). The same criticism is considered because EU treats this problem in the same way ((6.2) 2) i)).

\subsection{The Example of the Elucidation about Motivation and Obstructive Factors-Court Decision}

Tokyo High Court decision on 29 June 2004 (suit rescinding the trial decision for dissatisfaction against a decision of a final rejection $)^{22}$ is taken up to advance the argument in this section.

1) Case

The application invention is Japanese Patent Application No. Hei 9(1997)-294991 titled in "Halved type polish roll and its core metal fittings." The primary cited invention is a Publication of unexamined patent application (Kokai Publication) No. Hei 6(1994)-169817 titled in "The base pedestal for rotary brushes or rotary polish objects", and the secondary cited invention is a Publication of unexamined patent application (Kokai Publication) No.Shou 61(1986)-265104 titled in "A production method of the rotation roller for conveyance".

Both the application inventions and the primary cited invention are related to a polish roll. The points of difference between the application invention and the primary cited invention are (a) attachment means (8), and (b) that implanting ${ }^{22}$ Tunoda Brush cooperation v. Patent Office Commissioner (2004) "Collection of Decisions of Intellectual Property Cases" Supreme Court of Japan website. 
construction (22) of brushes is unknown in the primary cited invention. The inventive step of this application invention was denied, because there was motivation which applies the secondary cited invention to the primary cited invention about (b).

This article examines whether denial of motivation and the obstructive factor may be accepted as points of difference (b) based on the Opinion.

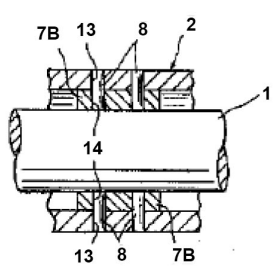

Front view showing the rotation axis (1), core metal fittings (2), an attachment pin (8), etc.

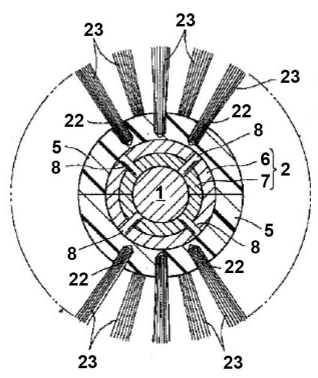

Side view
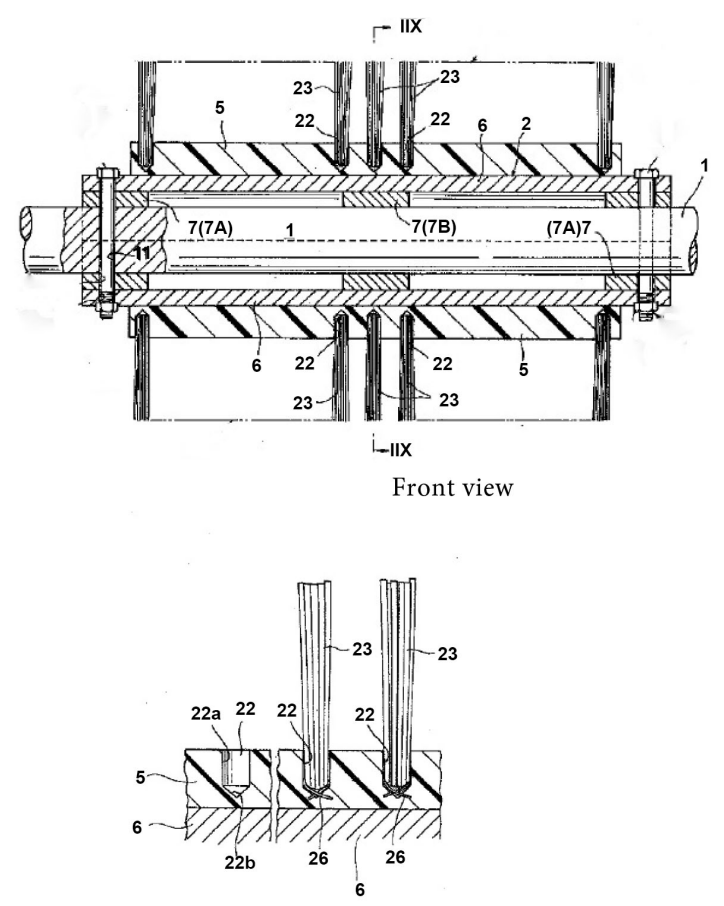

Brush bunch installation figure

\section{2) Decision}

If each invention described in the primary cited invention and the secondary cited invention belongs to the same technical field, as long as there will be no special circumstances, such as an obstructive factor is in the combination of both invention, generally the motivation of the combination of both invention exists.

A technical matter described in the secondary cited invention is the technology related to a brush, and because the polishing brush of the primary cited invention belongs to the same technical field, the motivation which applies the secondary cited invention to the primary cited invention exists.

A roller described in the secondary cited invention belongs to the same technical field where the roller of the primary cited invention is a revolving cylinder brush aiming at a polish, and both inventions have the same implant structure at the point which plants the hairs of a brush in the cylinder parts made of a synthetic resin. And although a roller described in the secondary cited invention is used for conveyance of agricultural products and their polish, it has sufficient motivation that implant structure described to the secondary cited invention will be applied to the primary cited invention.

The plaintiff asserted that the cylinder polishing brush of the application in- 
vention differs from the secondary cited invention in the fundamental composition, because the rotation number of a roller described in the secondary cited invention is comparatively low and its pushing down power is not so large not to cause a damage to crops, and on the contrary, the cylinder polishing brush of the application invention is used for surface finish of material to be polished, has high rotation number, and requires large pushing down power to attain the polish to a surface of metal. However, rotation number and pushing down power are design matters appropriately determined according to the object to be applied, and the difference in the composition of this point does not become an obstructive factor in the case that the abovementioned technical matter is applied to the primary cited invention.

\subsection{The Example of the Elucidation about Motivation and Obstructive Factors-Discussion Based on the Opinion}

1) Denial of motivation and acceptance of an obstructive factor

(1) Denial of Motivation

First, the decision says that if the technical field of the primary cited invention and the secondary cited invention is the same, there is generally motivation. However, the identity of a technical field must not only be understood formally, but also the substance must be considered from operation or function (principles and their use).

The decision mentioned that because the primary cited invention and secondary cited invention belong to the same technical field of the revolving cylinder brush aiming at a polish, there is motivation which applies the secondary cited invention to the primary cited invention.

However, considering the contents of the technical field in relation to both invention, the primary cited invention relates to a polish (grind), and secondary cited invention mainly relates to a conveyance and in addition aims at not a polish but a mere shine. Therefore, the brush used there naturally also becomes what differed in construction and the function /effect.

As mentioned above, in this case, the motivation by which the secondary cited invention is applied to the primary cited invention should be denied. The motivation is denied from the viewpoint of the principles and their use as a whole.

In this case, rather, with regard to the application invention (constitution $A+B+C)$, although a selection of the primary cited invention $(A+B)$ has no problem, there arises a question that a selection of the secondary cited invention (it should be constitution C) is even appropriate. Accordingly, the constitution of the secondary cited invention is considered correctly C' etc. which is different from C.

(2) Acceptance of the obstructive factors

In this case, in applying the secondary cited invention to the primary cited invention, the obstructive factors are accepted as follows (Author's Note: originally, as shown in Table 3, although the obstructive factors may be explained based on the principles and their use as a part, they will be also explained from the 
principles and their use as a whole so that the assertion about the obstructive factors together with the denial of the motivation may become more clear).

The application invention is going to obtain a firm structure in a whole polishing brush suitable for the unified structure of a core main body and an intervened metal fitting and improvement of the implant structure of the brush, because high rotation number and large pushing down power might be acting to polish metal etc. (principles as a whole).

The structure of implant hole of the brush in the secondary cited invention is merely the open hole, therefore, although this structure may be sufficient for the brush of a low rotation speed and small pushing down power, such a structure is not applicable to the primary cited invention or the application invention which aims at a high rotation number and large pushing down power (principle as a part).

On the other hand, for the secondary cited invention, rather, rotation number should be low and pushing down power must be small. For example, in the polish in the secondary cited invention, because the brush aims to make the dirt of an object (agricultural products) clean also, it must not hit too much strongly, and the damage etc. should not arise. First of all, because the secondary cited invention originally aims at conveyance of an object, if the pushing power is too strong or rotation number is too high, it is improper to conveyance (principle as a whole).

Moreover, the brush of the secondary cited invention is attached so that its hair planting inclines in the direction of the axis of rotation and the circumference for the purpose of conveyance. If this composition aims at polish, the tip of a brush will function, whereas, because it aims at conveyance (push), it is for use not only at the tip but also for using the whole brush (principle as a part). On the other hand, because the function of polish is rather spoiled in the application invention, it has no above inclination etc.

Therefore, if the function/effect (principles and their use) in which the abovementioned secondary cited invention has demonstrated, the purpose of polish of the primary cited invention will not be gained. That is, the obstructive factors are accepted.

2) Further consideration

(1) The view of court decision

According to the aforementioned Table 3 and Figure 4, the derivation of the conclusion of court decision can be explained as follows (Figure 5).

If the conception in this article is used, new principles $(\gamma, \delta$, etc. in Figure 4$)$ in ( $f$ ) will not be added to the principle $\alpha$ of the primary cited invention and the principle $\beta$ of secondary cited invention in above (a).

(2) The view where motivation is denied

In Figure 5, the principle of the second cited invention will not be $\beta$ (this is assumed as $\beta$ ). It is because the secondary cited invention has mainly rather the purpose and function of conveyance not only in the polish that the decision adopted (therefore, principle as a whole differs). 


\begin{tabular}{|c|c|c|}
\hline & \begin{tabular}{|} 
primary cited invention \\
$($ principle $\alpha)$
\end{tabular} & $\begin{array}{l}\text { secondary cited invention } \\
\text { (principle } \beta \text { ) }\end{array}$ \\
\hline (a) motivation & \multicolumn{2}{|c|}{ the same technical field } \\
\hline $\begin{array}{l}\text { (b) design matter } \\
\text { (f) obstructive factor }\end{array}$ & & $\begin{array}{l}\text { ow } \\
\text { small } \\
\text { ve factor) }\end{array}$ \\
\hline
\end{tabular}

Figure 5. Motivation, design matter and obstructive factors in decision, and the principles in the primary cited invention and the secondary cited invention.

(3) The view where obstructive factors are accepted

In the above, the principle $\delta$ of the part about conveyance is contained in the principle $\beta^{\prime}$ in the secondary cited invention, and if the secondary cited invention is applied, the function of the principle $\alpha$ in the polish in the primary cited invention will be reduced (it becomes $\alpha^{\prime}$ ). Therefore, the purpose of the primary cited invention cannot be reached.

Moreover, in considering the obstructive factors, it is conceivable that, so to speak, passive reason which the plaintiff stated in lawsuit as "in the secondary cited invention) the rotation number of a roller is comparatively low and its pushing down power is not so large not to cause a damage to crops" (p. 31), is insufficient. The plaintiff should rather have actively asserted that because the secondary cited invention has the purpose to convey objects (agricultural products) and to make their dirt clean also as described in p. 31, the structure of a brush shall be suitable for it, the rotation number of a roller should be low, pushing down power should also be not so strong, and they should be set up appropriately (based on different principles and their use). If he/she asserted this point, the recognition that "(they are) design matters appropriately determined" in the decision (p. 30) etc. would have less been made.

Although above (2) (3) are examples of a view which affirms an inventive step, persuasive principles and their use should be considered depending on a case. Generally, at first, it will be expedient to pay one's attention to the ways of their use by the principles as a part.

\subsection{Prevention of Hindsight}

Although an application invention must be judged based on the common general knowledge of engineering at the application time, because an examination is made after application, hindsight, that is, ex-post decision based on the knowledge after the application or means for solving the problem described in the application documents tends to be carried out. Therefore, it must be kept in mind.

1) Examination guidelines

Although the previous Examination Guidelines in Japan had regulations that 1) a cited invention is understood along with the its context of the cited literature; 2) ex post facto analyzing on the premise founded on the knowledge acquired from the specification of the patent application, there is a tendency where a person ordinarily skilled in the art seems to have been able to conceive easily, therefore, cautions are required, it was deleted as a matter of course. 
However, the way of regulation should be made a little more concrete, and it is considered better to prepare regulation. Naturally, the court decisions have accepted the prevention of hindsight.

2) Relation between the hindsight and the principles and their use of the Opinion

According to the Opinion, because focusing on the difference of the principles and their use between the application invention and the prior inventions, not on the description of the specification etc., is focused, it is hard to bring the hindsight. However, the above difference which is understood at the time of application should be taken up, and must not be based on the difference understood later.

In addition, the Opinion also helps an exclusion of hindsight, because, as a criterion of determination, it adopts not the act of whether there was a suggestion in it, but the principles as an object, and does not give too much importance to the problems to be solved either.

\section{Comparison of the Opinion with the Examination Guidelines and Court Decision about the Inventive Step in U.S.A. and EU}

With regard to Examination Guidelines about the inventive step in U.S.A. and $\mathrm{EU}$, the relation with the Opinion is more concretely discussed, paying attention to the relation with Examination Guidelines in Japan, and the difference among Japan, U.S.A, EU and the Opinion is arranged.

\subsection{Comparison with Examination Guidelines and Court Decision in U.S.A.-Also Paying Attention to Obstructive Factors and a Prevention of Hindsight}

1) TSM test has common parts to "motivation" of the inventive step denial factor in Examination Guidelines in Japan.

2) Examination Guidelines based on KSR court decision

(1) Relation with the inventive step denial factors and inventive step affirmative factors in Examination Guidelines in Japan will be considered as follows:

1) About aforementioned (4.4) 2) (4) a), it corresponds to "mere aggregation of prior art" of a denial factor.

2) About b) in the above same description, it is considered that it corresponds to "mere aggregation of prior art" or "design variation of primary prior art" of denial factor.

3) About c) d) e) in the above same description, it is considered that they correspond to "design variation of the primary prior art" of denial elements.

4) About f) in the above same description, it is considered that it does not correspond to "advantageous effect" of affirmative factor.

5) About g) in the above same description, it is considered that it corresponds to being of "motivation" for a denial factor.

(2) It is considered that although denial factors and affirmative factors of the 
inventive step in Examination Guidelines in Japan are chosen inductively based on a practice too, it is classified better, compared with a portion described as Examination Guidelines in U.S.A.

Therefore, regarding the above, the same interpretation and a criticism can be applied as the description in a determination criterion of an invention step based on the Opinion aforementioned in (2.6) 3) (2).

3) Obstructive factors. Prevention of hindsight

(1) Obstructive factors

They are explained in the court decision cited in Examination Guidelines. Obviousness may be rebutted by showing that the cited technology/engineering "takes away from" (Author's note: principle and its use in the minus direction said in the Opinion) the claimed invention. The examples of the obstructive factor are as follows: for the person skilled in the art to stop to do or to be led in the different direction from the direction which the applicant adopts, or for the result to occur in which the product cannot move (Mcginn, Shahota, \& Hirata, 2014).

(2) Prevention of hindsight

Examination Guidelines explain that "any judgments on obviousness... (should) take into account only knowledge which was within the level of ordinary skill in the art at the time the claimed invention, and does not include knowledge gleaned only from applicant's disclosure" (M.P.E.P. § 2145X). It shows clearly prevention of hindsight.

\subsection{Comparison with Examination Guidelines in EU-Also Paying Attention to Obstructive Factors and a Prevention of Hindsight}

1) Examination Guidelines

(1) Objective technical problem

This seems to be based on the intention which is going to objectively establish a problem to be solved.

a) The problem to be solved as described in an application invention cannot necessarily trust its accuracy, but b) the difference of the elements of a claim and its effects (principles and their use) is objective.

However, the above approach is not considered appropriate with the reason as follows:

Regarding the point which is establishing a technical subject objectively apart from the problem to be solved of an application invention, it can be said that too many factors are incorporated into the problem to be solved which is prior to the invention, and, so to speak, it is top heavy. The view which avoids a research of the invention act itself and substitutes motive of an act with the problem to be solved prior to the motive cannot be adopted.

The relation between this objective technical problem and the problem to be solved of an application invention is also ambiguous. Objectification is aspired to, but there is a possibility that the establishment of a problem to be solved may 
be made arbitrarily by a person who makes the determination (examiner). Extremely, even contrary to an intention of an applicant is conceivable.

Such a way to establish a problem to be solved may be considered as a direction which lapses into hindsight, because it can determine an obviousness incorporating many factors in the problem to be solved at the application time, at the subsequent determination time.

Depending on the prior art, an establishment of a problem to be solved may be sometimes difficult (for example, the document except for an official gazette and working technology).

Like the Opinion, it seems that a problem to be solved described in an application invention may be applied to determine an obviousness. Because an achievement of a problem to be solved appears in an effect of an invention, it is thought that the question raised from a problem to be solved can be checked from the effect.

However, the intention to want to objectify a problem to be solved more can be understood. Such a thought can be acceptable from the situation which considers, in a united manner, the intent of many member nations, especially EU. Moreover, an attention to the principles and their use from the starting point of determination of an inventive step is the same as the Opinion, and is appropriate.

However, as criticized above, there is no need to introduce objective technical problem, so to speak, by force, and it is considered like the Opinion that it is sufficient to be adopted from principles and their use more directly.

(2) Could-would approach

This approach is based on making the determination by teaching etc. specifically, therefore, the same criticism explained in aforementioned (2.6) 3) (2), (4.5) is approved.

First of all, nuance between "could" and "would" is unclear for not English-speaking people.

2) Obstructive factors. Prevention of hindsight

(1) Obstructive factors

Examination Guidelines provides that "if two disclosures considered as a whole could not in practice be readily combined because of inherent incompatibility in disclosed features essential to the invention, the combining of these disclosures is not normally regarded as obvious" (E.P.C. Part G Chapter VII 6).

(2) Prevention of hindsight

Examination Guidelines provides that "Once a new idea has been formulated, it can often be shown theoretically how it might be arrived at, starting from something known, by a series of apparently easy steps. The examiner must be wary of ex post facto (Author's Note: hindsight) analysis of this kind... In all cases the examine must attempt to visualize the overall state of the art confronting the skilled person before the applicant's contribution, and he must seek to make a 'real-life' assessment of this..." (Part G Chapter VII 8). 


\subsection{Difference between Examination Guidelines in Japan, U.S.A. and EU, and the Opinion}

1) In conclusion, there seems to be no large difference in portion mentioned in Figure 6 among Japan, U.S.A. and EU in a thinking manner.

This is, because, it is determined by motivation, teaching, suggestion, etc. which are the motive of an act as easiness in conceiving an invention or an obviousness to an application invention from a prior art.

In the abovementioned examination guidelines, the prevention of hindsight and obstructive factors can be understood almost similarly, according to a court decision aside from provisions.

After all, it can be said that an establishment of an objective technical problem in problem-solution approach in EU is only characteristic. The problem to be solved such as the above is not prepared in Japan and U.S.A.

The difference of constitutions between an application invention and a cited invention which is adopted in the said objective technical problem is common to the difference of both invention in Japan and U.S.A. On the other hand, it is considered that the effect of application invention taken with the objective technical problem is common to the principles and their use in the application invention.

2) The Opinion is based on the commonality/difference of principles and their use, because principles and their use is a fact which is a subject of act, and is objective. Thereby, it is considered that the determination about an inventive step can be understood in a unified manner through the examination guidelines regarding it in Japan, U.S.A. and EU. An effect is a fact itself. On the other hand, principles and their use are considered to be abstracted and have a more suitable phase in a technical comparison.

\begin{tabular}{|c|c|c|c|c|}
\hline & & \multicolumn{3}{|c|}{ Can an application invention is reached starting from a prior art? } \\
\hline & $\begin{array}{r}\text { problem to } \\
\text { be solved }\end{array}$ & & prevention of hindsight & obstructive factors \\
\hline Japan & & \begin{tabular}{||} 
reasoning \\
motivation \\
suggestion \\
\end{tabular} & $\begin{array}{l}\text { No express provision } \\
\text { exists, } \\
\text { But exists in court decision. }\end{array}$ & Express provision exists. \\
\hline U.S.A. & & \begin{tabular}{|l} 
TSM test \\
(teaching, suggestion, \\
motivation) \\
KSR court decision \\
\end{tabular} & Express provision exists. & Express provision exists. \\
\hline $\begin{array}{l}\text { EU } \\
\text { (problam-sollution } \\
\text { approach) }\end{array}$ & $\begin{array}{l}\text { objective } \\
\text { technical } \\
\text { problem }\end{array}$ & $\begin{array}{l}\text { “" Could-Would , } \\
\text { approach } \\
\text { (teaching, motivation) }\end{array}$ & Express provision exists. & Express provision exists. \\
\hline \multirow[t]{2}{*}{ the Opinion } & & $\begin{array}{l}\text { commonality/difference } \\
\text { of principles and their } \\
\text { use as a whole } \\
\text { (principle of plus } \\
\text { direction) }\end{array}$ & \begin{tabular}{|l|} 
at an application time \\
$\begin{array}{l}\text { commonality/difference of } \\
\text { principles and their use }\end{array}$ \\
\end{tabular} & $\begin{array}{l}\text { commonality/difference of } \\
\text { principles and their use as a } \\
\text { part } \\
\text { (principle of minus } \\
\text { direction) }\end{array}$ \\
\hline & & comm & nality/difference of principles & and their use \\
\hline
\end{tabular}

Figure 6. Difference between the Examination Guidelines about the inventive step in Japan, U.S.A. and EU, and the Opinion. 
The Opinion will determine an inventive step by taking principles and their use as a whole and as a part, and plus direction and minus direction, and besides appropriate judgment time.

Therefore, according to the Opinion, the handling of obstructive factors is logical and concrete compared with that of Japan which is mentioned in (5.1) 2), that of U.S.A mentioned in (6.1) 3) (1), and that of EU mentioned in (6.2) 2) (2).

The Opinion is hard to raise hindsight primarily.

\subsection{The Advantage about Obstructive Factors and Prevention of Hindsight Based on the Opinion}

Regarding the subject of determination etc. in Japan, U.S.A, EU, and the Opinion which arranged the above mentioned in this article, and the advantage of adopting the Opinion about obstructive factors and prevention of hindsight can be seen collectively in Figure 7.

\begin{tabular}{|c|c|c|c|c|c|c|}
\hline & \multicolumn{4}{|c|}{ object of determination etc. } & \multirow{2}{*}{$\begin{array}{l}\text { prevention } \\
\text { of } \\
\text { hindsight }\end{array}$} & \multirow{2}{*}{$\begin{array}{l}\text { obstructive factors } \\
\text { (regarding secondary } \\
\text { invention to primary } \\
\text { invention) }\end{array}$} \\
\hline & prior to invention & motive & object & & & \\
\hline Japan & $\begin{array}{l}\text { (problem to be - } \\
\text { solved) }\end{array}$ & 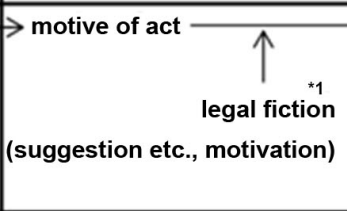 & \begin{tabular}{l|} 
act \\
non-easiness in \\
conceiving
\end{tabular} & & $\begin{array}{l}\quad{ }^{* 5} \\
\text { easy to } \\
\text { lapse into } \\
\text { hindsight }\end{array}$ & $\begin{array}{l}{ }^{*}{ }^{*} \\
\text { subjective being } \\
\text { contrary to the } \\
\text { purpose of the primary } \\
\text { cited invention etc. }\end{array}$ \\
\hline U.S.A. & & $\begin{array}{l}\text { motive of act } \frac{1}{1}{ }^{* 1} \\
\text { legal fiction } \\
\text { (TSM (teaching, } \\
\text { suggestion, motivation)) }\end{array}$ & \begin{tabular}{c|} 
act \\
nonobviousness \\
\end{tabular} & & \begin{tabular}{|l|}
\multicolumn{1}{|c|}{$* 5$} \\
easy to \\
lapse into \\
hindsight
\end{tabular} & \\
\hline EU & $\begin{array}{l}\text { obstructive } \\
\text { technical problem } \\
\text { (orientation of } \\
\text { determination) }\end{array}$ & $\begin{array}{l}\text { Could-would approach } \\
\text { legal fiction } \\
\text { (teaching "which would", ) }\end{array}$ & $\longrightarrow$ act & \begin{tabular}{|r|}
$* 3$ \\
objectivity \\
subjectivity
\end{tabular} & $\begin{array}{l}\quad * 5 \\
\text { easy to } \\
\text { lapse into } \\
\text { hindsight } \\
\text { further } \\
\text { more }\end{array}$ & \\
\hline $\begin{array}{c}\text { the } \\
\text { Opinion }\end{array}$ & $\left(\begin{array}{c}\text { technical field, } \\
\text { principle to be } \\
\text { solved, } \\
\text { operation or } \\
\text { function }\end{array}\right)$ & & act $\leftarrow$ fegal fiction 2 & $\begin{array}{l}\text { including } \\
\text { subjectivity } \\
\text { object }\end{array}$ & \begin{tabular}{l}
\multicolumn{1}{c}{${ }^{* 6}$} \\
difficult to \\
lapse into \\
hindsight
\end{tabular} & $\begin{array}{l}\text { reduction (setoff) of } \\
\text { the utility of the } \\
\text { primary cited invention } \\
\text { (offset) is determined } \\
\text { based on principles } \\
\text { and their use. }\end{array}$ \\
\hline
\end{tabular}

Figure 7. An object of determination etc. and advantage which takes the Opinion about prevention of hindsight and obstructive factors. 
${ }^{*} 1$ The legal fiction of the existence or non-existence of an act (invention) is made with the existence or non-existence of motive of an act.

*2 The legal fiction of the existence or non-existence of an act is made with the objective fact which is the object of the act.

*3 The objective technical problem is regarded as the orientation for determination of subjective Could-would approach.

${ }^{*} 4$ The factor including subjectivity is regarded as a reference of orientation for determination of the degree of a difference of the objective principles and their use. For details, refer to (4.5) 2).

*5 It is easy to lapse into hindsight in the practice in Japan, U.S.A and EU, becausethe determination is made in a subjective act in them. In EU, because the effect of application invention is added to an establishment of an objective technical problem, it may come out further.

*6 According to the Opinion, because the objective principles and their use are set as the object of determination, it is hard to lapse into hindsight.

${ }^{\star} 7$ According to the practice in Japan, U.S.A and EU, subjective determination is needed, such as being contrary to the purpose.

${ }^{*} 8$ According to the Opinion, what is necessary is just to determine the objective effect (utility) based on principles and their use.

\section{Unified Interpretation Based on the Opinion and the Way of Application of the Opinion}

\subsection{Validity of the Unified Interpretation Based on the Opinion}

1) If a determination is made on the basis of the commonality/difference of the principles and their use, Examination Guidelines on the inventive step in Japan, U.S.A. and EU can be understood with unification. Also, a more objective determination becomes possible. Furthermore, the direction of farther quantification is also considered.

However, practically for the sake of the convenience of thinking and explanation, the commonality/difference of the principles and their use can be determined, following the form of thinking to apply the secondary invention to the primary invention etc. which is used in the abovementioned examination guidelines.

2) The determination of the inventive step leaves from the objective technical problem and the cited invention in EU. However, the objective technical problem takes in the principles and their use of the application invention and the cited invention. Therefore, Author thinks that the attention should be directly paid to the commonality/difference of the principles and their use of the application invention and the cited invention.

\subsection{The Way to Carry Out Actual Application to the Determination of the Inventive Step by the Opinion}

1) Consider the necessity and the detail of application of principles and their 
use in the following order.

i) If the inventive step is clear from suggestion etc., the determination will be made based on it.

This is the same as Examination Guidelines of Japan, U.S.A. and EU.

ii) (a) Relation of technical fields, (b) similarity of problems to be solved, and (c) similarity of operations or functions which are used for determination of the existence of the motivation of Examination Guidelines in Japan, including a subjectivity, are used in this order as reference to orient the determination based on principles and their use of the Opinion ((4.6) 2) iii) ref.).

iii) The difference of principles and their use is examined in detail.

In many cases which become problematic in a court decision etc., a more detailed examination of principles and their use will be needed.

2) Finally, although a determination of the inventive step depends on the difference (object) of principles and their use, if the orientation including subjectivity can be used as a preceding step like above 1) ii), it will be used.

Although problem-solution approach finally makes a determination based on the subjectivity of whether there is teaching, the orientation by the objective technical problem is made. That is, subjectivity and objectivity are reverse.

3) The abovementioned thing is similarly useful for examining the obstructive factors of the inventive step. That is, the actual examination guidelines are also taken into consideration, and comprehension will be made using the principles and their use of plus or minus.

\section{Conflicts of Interest}

The author declares no conflicts of interest regarding the publication of this paper.

\section{References}

Brian Arthur, W. (2009). The Nature of Technology: What It Is and How It Evolves. London: Penguin Books.

Chou, C. (2016). Comparative Analysis of Inventive Step/Nonobviousnees Standard and Study Thereof-From the Aspect of "the Problem to Be Solved". IIP Bulletin, 25, 1-10. http://www.iip.or.jp/e/summary/pdf/detail2015/e27_summary_Chou.pdf

Kageyama, K. (2015). Recognition of Inventor/Joint Inventors and Product-by-Process Claims-Based on Consideration of Categorization into Physical-Object \& Material Inventions and Formation Process of Inventions. Germany: LAP Lambert Academic Publishing.

Kageyama, K. (2018a). Analysis of the Invention through an Experiment for Clarifying a Problem of Patent Law-Based on Abstraction of Invention by "Principle and its Use" and "a Shape, a Structure, Properties and Their Transformation of an Article". Beijing Law Review, 9, 661-696. https://www.scirp.org/Journal/PaperInformation.aspx?PaperID=88797

Kageyama, K. (2018b). Unified Approach for Inventive Step and Claim Interpretation-Analysis Based on the Physical/Chemical Principle and Ways of its Use, and the Categorization of the Physical-Object/Material Invention. Germany: LAP Lambert Academic Publishing. 
Mcginn, S. M., Shahota, S. S., \& Hirata, T. (2014). About Comparison of the Inventive Step in Japan and Nonobviousness in the U.S.A. Patent 2014.67, 3.

Schramm, L. (2014). The Pathway from Discovery to Invention to Innovation. Saskatchewan Research Council, Sept. 3. https://www.src.sk.ca/node/374

Tokkyo-chō and Shadan-hōjin Hatusumei-kyōkai Ajia Tahiheiyō Kōgyoshoyūken Sentā (APIC), Tsukanaka, T. Coop. (2011). Hatsumeino Shinposei. Inventive Step of an Invention. 